\title{
Psychology and morality of political extremists: evidence from Twitter language analysis of alt-right and Antifa
}

\author{
Meysam Alizadeh ${ }^{1 *}$ (D), Ingmar Weber ${ }^{2}$, Claudio Cioffi-Revilla ${ }^{3}$, Santo Fortunato ${ }^{4}$ and Michael Macy ${ }^{5}$
}

\author{
*Correspondence: \\ alizadeh@princeton.edu \\ 'Empirical Studies of Conflict \\ Project, Woodrow Wilson School of \\ Public and International Affairs, \\ Princeton University, Princeton, USA \\ Full list of author information is \\ available at the end of the article
}

\begin{abstract}
The recent rise of the political extremism in Western countries has spurred renewed interest in the psychological and moral appeal of political extremism. Empirical support for the psychological explanation using surveys has been limited by lack of access to extremist groups, while field studies have missed psychological measures and failed to compare extremists with contrast groups. We revisit the debate over the psychological and moral appeal of extremism in the U.S. context by analyzing Twitter data of 10,000 political extremists and comparing their text-based psychological constructs with those of 5000 liberal and 5000 conservative users. The results reveal that extremists show a lower positive emotion and a higher negative emotion than partisan users, but their differences in certainty is not significant. In addition, while left-wing extremists express more language indicative of anxiety than liberals, right-wing extremists express lower anxiety than conservatives. Moreover, our results mostly lend support to Moral Foundations Theory for partisan users and extend it to the political extremists. With the exception of ingroup loyalty, we found evidences supporting the Moral Foundations Theory among left- and right-wing extremists. However, we found no evidence for elevated moral foundations among political extremists.
\end{abstract}

Keywords: Political extremism; Psychological profile; Language analysis; LIWC; Moral foundations theory

\section{Introduction}

Since late 2016, several hate and violent rallies have been held in U.S., U.K., Poland, Germany, Canada, and Russia, Jewish and African-American institutions and Mosques across the U.S. have been threatened with armed protests or attacked by lone actors, and immigrants have been targeted in suspected hate crimes in the United States and other countries. Many of these incidents were linked to far-right and alt-right supporters, which include but not limited to Neo-Fascist Movement in Italy (Castelli Gattinara et al. [18]), National Action in Britain (Macklin [63]), right-wing militants in Russia (Enstad [32]), Hive terrorism and refugee crisis in Germany (Koehler [56]), Death Squad and the Hungarian Arrows National Liberation Army in Hungary (Mareš [65]), and Racialist, Anti-Federalist, and Christian Fundamentalist ideologies in the U.S. (Sweeny and Perliger [90], Windisch et al. [101]).

(c) The Author(s) 2019. This article is distributed under the terms of the Creative Commons Attribution 4.0 International License (http://creativecommons.org/licenses/by/4.0/), which permits unrestricted use, distribution, and reproduction in any medium, provided you give appropriate credit to the original author(s) and the source, provide a link to the Creative Commons license, and indicate if changes were made. 
On the other hand, during 2016 and 2017, far-left movements in the U.S. such as Antifa were actively engaging in violent actions attacking alt-right demonstrators, protest against alt-right speakers in universities, and threat to disrupt far-right affiliated parades (Beinart [13]). A high-profile example of such incidents was the case of Charlottseville, Virginia in August 2017, at which members of Antifa clashed with alt-right supporters using some violent methods (LaFree [62]). While the antifascist movements seemed to be disappeared with the end of WWII, they are on rise in the United States and Europe, in part due to the growth of neo-Nazism (LaFree [62], Arlow [10]).

This recent rise of hate and violence demands better understanding of the causes of political extremism and its actors and has caught the attention of researchers across various domains (e.g. Bonikowski [15], Jasko et al. [48], Kurzman et al. [61], Kruglanski et al. [59], Webber et al. [99]), including political psychology. Does the appeal of extremist groups reflect psychological or moral differences? In other words, do political extremists possess distinguished psychological or moral profiles compared to non-extremists?

This question taps into competing psychological explanations for involvement in extremist political groups. In psychology, more than 60 years of research has focused on predictors of left- versus right-wing ideology (e.g. Adorno et al. [1], Altemeyer [8], Sidanius [83], Rokeach [79]). As the authors of The Authoritarian Personality put it: "Ideologies have for different individuals, different degrees of appeal, a matter that depends upon the individual's needs and the degree to which these needs are being satisfied or frustrated" (Adorno et al. [1]). In other words, political psychologists believe that our beliefs serve psychological functions and there are natural correspondences between our psychological states and political orientation (Jost [49]).

Although the literature on psychological and moral covariates of political attitudes and orientation is rich, the extent to which its findings can be generalized to both extremes of the political spectrum (left and right) is questionable (Greenberg and Jonas [39], Jost et al. [53]). Indeed, individual psychological and moral correlates of non-violent left- and right-wing political extremists have not been well-researched (Prince [76]). One obvious reason for this shortage of research is simply the fact that extremists would not volunteer to participate in experimental or field studies.

Research on the susceptibility to political extremism has relied on surveys and ethnographic studies. Surveys have been administered to random samples as well as convenience samples (e.g. college students) to identify those whose responses fall at the extremes of the liberal-conservative spectrum (e.g. Jost et al. [53], Kruglanski et al. [58], van Prooijen et al. [96]) and who believe that the realization of fundamental social and economic changes requires militant action outside the electoral process. An immediate problem is that elicited responses to an interviewer are not equivalent to voluntary expressions of support for, agreement with, and endorsement of extremist groups and activities, including those that are non-violent. Other studies have used field observation of extremist groups (Canetti-Nisim et al. [17], Atran and Ginges [11]), but these works lack psychological measures, fail to compare political extremists with proper control groups, and suffer from selection bias. Computational studies also suffer from lack of appropriate data for validation (e.g. Alizadeh et al. [4, 6], Flache and Macy [35], Alizadeh and Cioffi-Revilla [2, 3], Ravandi and Mili [77]).

Widespread use of social media by extremist organizations and their followers provides researchers with unprecedented opportunities to study the profiles of those who are sus- 
ceptible to extremist appeals (e.g. Magdy et al. [64], Rowe and Saif [81], Davidson et al. [24], Ferrara [33]). Twitter messages have been shown to reveal underlying psychological attributes that are reflected in word usages, a method which goes back to 1950s (e.g. the Harvard General Inquirer) and recently mastered by James Pennebaker (Pennebaker et al. [70]).

In this paper, we introduce a novel data set to study the psychological and moral profiles of political extremists in the United States. We analyze Twitter messages written by over 500,000 American followers of non-violent U.S. extremist individuals/organizations and identified the true supporters of extreme ideologies, then sampled 10,000 Twitter users from the identified extremists pool. We compare the text-based indicators of psychological and moral variables with results for followers of the five most liberal and the five most conservative U.S. Senators according to their 2018 DW-NOMINATE scores (Poole and Rosenthal [74]). We control for other contributing factors including the followers count, friends count, action count, action frequency, and tenure by using inverse propensity score weighting.

In Sect. 2, we review various psychological theories associated with the role of certainty, anxiety, happiness, and moral foundations on political orientation, and whether or not they are generalizable to the political extremism context. We discuss opposing theories and develop hypotheses to be tested with our new data set. We explain our definition of political extremism, data collection procedure, plausible confounding variables and how to adjust for them, and methods to infer psychological and moral variables from users' tweets in Sect. 3. We present our results in Sect. 4 and conclude the paper in Sect. 5.

\section{Theoretical and empirical background}

\subsection{Psychological constructs and political extremism}

The general form of hypothesis that we explore here is whether or not there exist some psychological and moral variables that covary with political orientation and extremity. Specific variables that have been hypothesized or empirically shown to correlate with political ideology include ambiguity intolerance (Frenkel-Brunswik [36], Fibert and Ressler [34]), uncertainty avoidance (Sorrentino and Roney [88]), fear and aggression (Adorno et al. [1], Altemeyer [9]), negative affect (Tomkins [94]), need for cognitive closure (Kruglanski and Webster [60], Kruglanksi [57]), need for order and structure (Altemeyer [9], Smith and Gordon [87]), integrative complexity (Sidanius [83, 84], Tetlock [93]), anxiety (Greenberg et al. [41]), group-based dominance (Pratto et al. [75]), system justification tendencies (Jost and Banaji [50]), self-esteem (Jost et al. [51]) and moral foundations (Haidt and Joseph [45], Haidt and Graham [44]). However, only few of these research explicitly investigated the extent to which their findings are driven by or generalizable to political extremists. On the other hand, not all of these variables can be measured based on social media data. Therefore, in this paper, we only focus on those variables that have been hypothesized to correlate with political extremism and are measurable through social media data. This includes certainty, anxiety, positive and negative emotions, and the five moral constructs discussed in the Moral Foundations Theory (Haidt and Joseph [45]).

It should be noted that we do not yet know the relationship between the text-based indicators of psychological and moral variables and traditional ways of assessing them in psychology, nor do we propose our method as a replacement for them. Rather, we want to highlight the potential of online data as a complement to existing methods of studying psychological and moral profiles of political extremists. 


\subsubsection{Certainty}

Generally, two opposing views have been proposed for how certainty covaries with political extremism. The mainstream and well-studied view is that of negative relationship between political extremism and certainty. They argue that naturally extremism involves a sort of deviancy from what most people tend to believe in or consider reasonable. The extent to which people deviate from the norm constructs a spectrum wherein some beliefs or behaviors may consider more extreme than the others. The relationship between political extremism and certainty rises from the cost and difficulty associated with maintaining the deviant position in a society. In fact, being a nonconformist requires effort and "people can save themselves considerable effort and energy by going along with the crowd" (Alquist et al. [7, p. 81]). Whether the norm is established through central tendency of people or an authority figure, deviating from it is challenging and requires substantial energetic resources (Kruglanski et al. [58], Kruglanski et al. [59]). Because of that difficulty, extremists tend to protect their nonconformity from majority pressures by holding them with considerable certainty (Webber et al. [99]). In a similar discussion, Greenberg and Jonas [39] proposed that, whether left or right, needs to avoid uncertainty would be higher for extremists than those at the center.

H1a: Political Extremists score higher on text-based indicators of certainty compared to their non-extremist counterparts.

On the other hand, Sidanius [84] observes that holding extreme attitudes requires some degree of sophistication and complexity. According to this view, extremists can manage the pressure associated with their deviance and may have higher uncertainty tolerance. Empirical evidence based on questionnaire study of one hundred and eight undergraduate students reveals that uncertainty tolerance (rather than avoidance) is associated with ideological extremity, especially left-wing extremism (Jost et al. [53]). Therefore, assuming that higher uncertainty tolerance means or is associated with less certainty, we can hypothesize that:

H1b: Political extremists score lower on text-based indicators of certainty compared to their non-extremist counterparts.

H1c: Left-wing extremists score lower on text-based indicators of certainty compared to right-wing extremists.

\subsubsection{Anxiety}

Similar to certainty, research on the relationship between political extremism and anxiety or mental distress is inconclusive. The extant literature identifies two perspectives. Building on the empirical findings that conservatives score higher than liberals on the "perception of dangerous world" scale (Altemeyer [9], Duckitt [30]), first group of theories postulate that right-wing extremists suffer from greater anxiety than others. Jost et al. [51] found that fear of threat and loss and death anxiety are significant predictors of political conservatism. While Crowson et al. [23] and Greenberg and Jonas [40] argue that anxiety is associated only with extreme attitudes, Jost et al. [53] showed that it is associated with political conservatism in particular and not ideological extremity in general. More recently, Roccatto and Russo [78] found a positive correlation between anxiety and right-wing extremism under societal threat to safety condition.

H2a: Right-wing extremists score higher on text-based indicators of anxiety than others. 
A second group of researchers, drawing on Terror Management Theory (Greenberg et al. [42]), Social Identity Theory (Tajfel [91]), the frustration-aggression hypothesis (Dollard et al. [29]) and System Justification Theory (Jost and Hunyady [52]), argue that ideological extremity is a buffering factor for psychological health. According to this view, holding extreme viewpoints yields lower levels of anxiety. In two separate studies which asked subject to fill out a questionnaire, Van Hiel and De Clercq [95] found less adverse effects of facilitators of mental distress among those participants who score higher on authoritarianism scale. Their results further showed that "authoritarianism acts as a buffer against mental distress" for people with D-type personality. More recently, drawing on longitudinal survey data from 18 countries, Vargas-Salfate et al. [97] concluded that conservatism is negatively and significantly related to anxiety and depression. Furthermore, it is argued that, unlike their moderate counterparts, supporters of the far right show authoritarian inclination (Bobbio [14, pp. 72-79]). Thus, we can hypothesize that:

H2b: Right-wing extremists score lower on text-based indicators of anxiety than others.

\subsubsection{Happiness}

There is a longstanding debate about the relationship between conservatism and happiness. A public opinion survey conducted by Pew Research Center in 2006 showed that whereas $47 \%$ of conservative republicans considered themselves as "very happy", only $28 \%$ of liberal democrats felt so (Taylor et al. [92]). Since then, many studies have supported or rejected these results. Drawing on system-justification theory and data from ten countries, Napier and Jost [66] found that right-wing ideology is positively correlated with happiness and life satisfaction, and that there exists a happiness gap between left- and right-wing supporters. Using a longitudinal survey of online subjects from 18 countries, Vargas-Salfate et al. [97] showed that having system justification attitude is associated with higher life satisfaction. Earlier work has identified conservatism as a form of system-justifying belief (Jost and Hunyday [52]).

However, right-wing ideology has been reported to be negatively correlated with indicators of psychological well-being such as life satisfaction, positive affect, or absence of negative affect. For example, Peterson and Duncan [72] found that women who score high on authoritarian scale have less positive affect compared to those who score low on the same scale. In another study, Duriez et al. [31] showed that authoritarianism is associated with developing depressive symptoms. Moreover, there are studies who found no significant relationship between right-wing attitudes and psychological wellbeing (e.g. Butler [16], Onraet et al. [68]).

Although there are many empirical studies on the relationship between positive emotion and political orientation, our search to find a related study on political extremity was fruitless. To fill this gap and building on the observed robust occurrence of a linear effect (Jost et al. [51]), we assume that the relationship between negative/positive emotion and political orientation is monotonously and uniformly linear. Hence, if these findings are true, one could hypothesize that:

H3a: Conservatives score higher on text-based indicators of positive emotion and lower on negative emotion compared to liberals.

H3b: Extremists score higher on text-based indicators of positive emotion and lower on negative emotion compared to non-extremists.

H3c: Right-wing extremists score higher on text-based indicators of positive emotion and lower on negative emotion compared to left-wing extremists. 
On the other hand, according to the second set of studies, we hypothesize that:

H3d: Liberals score higher on text-based indicators of positive emotion and lower on negative emotion compared to conservatives.

H3e: Extremists score lower on text-based indicators of positive emotion and higher on negative emotion compared to conservatives.

H3f: Right-wing extremists score lower on text-based indicators of positive emotion and higher on negative emotion compared to left-wing extremists.

\subsection{Moral foundations and political extremism}

Moral psychologists have argued that the left differs from the right in the emotional resonance with different "moral foundations" (Haidt and Joseph [45], Haidt and Graham [44], Haidt [43]). The Moral Foundations Theory (MFT) proposes that liberals endorse values of fairness/reciprocity (e.g. the number one principle in making laws should be ensuring fair treatment) and avoidance of harm (e.g. compassion for those who are suffering) more enthusiastically than conservatives, whereas conservatives endorse values of ingroup loyalty (e.g. loyalty to ingroup is more important than individual concerns), obedience to authority (e.g. law makers should respect traditions), and enforcements of purity, divinity, and sanctity standards (e.g. the government should help people live virtuously) more enthusiastically than liberals. Graham et al. [38] developed methods to measure each of these five moral foundations and empirically supported the above hypotheses about moral differences between liberals and conservatives. The observed pattern has been replicated many times (e.g. Davies et al. [25], Day et al. [27], Nilsson and Erlandsson [67], Yilmaz et al. [102]). However, the extent to which MFT can be generalized to political extremists is yet to be tested with empirical data. Therefore, our first set of hypotheses about the relationship between political extremism and MFT can be stated as followings:

H4a: Left-wing extremists score higher on text-based indicators of fairness/reciprocity than right-wing extremists.

H4b: Left-wing extremists score higher on text-based indicators of harm avoidance/care than right-wing extremists.

H4c: Right-wing extremists score higher on text-based indicators of ingroup loyalty than left-wing extremists.

H4d: Right-wing extremists score higher on text-based indicators of obedience to authority than left-wing extremists.

H4e: Right-wing extremists score higher on text-based indicators of purity than left-wing extremists.

Furthermore, in order to link MFT to political extremism, Graham and Haidt [37] argue that since successful political movements must have a story that explains the current problems and their solutions (Westen [100]), MFT "provides the most comprehensible account of the hooks in the moral mind to which a good ideological narrative can attach". While previous research tended to define extremism in terms of only harm avoidance/care moral foundation, Graham and Haidt [37] suggest that it can be defined based on other moral foundations as well. They further argue that the "elevation" or "sacralization" of a moral foundation is a major cause of extremism. For example, in case of white supremacists, the narrative provided in The Turner Diaries (Pierce [73]) emphasizes on ingroup and purity foundations. The white race and its pure blood are sacralized, and self-sacrifice and loyalty for its protection and survival are painted as moral ideals. Or in case of the Weather 
Underground, which was a left-wing extremist group in 1970s, their primary area of sacralization was black victims in white America, which led them to possess sacralized harm and fairness moral foundations. Hence, our second set of hypotheses regarding the association between MFT and political extremism can be stated as followings:

H4f: Left-wing extremists score higher than liberals on text-based indicators of fairness.

H4g: Left-wing extremists score higher than liberals on text-based indicators of harm avoidance.

H4h: Right-wing extremists score higher than conservatives on text-based indicators of ingroup loyalty.

H4i: Right-wing extremists score higher than conservatives on text-based indicators of obedience to authority.

H4j: Right-wing extremists score higher than conservatives on text-based indicators of purity.

\section{Data and methods}

\subsection{Identifying political extremist groups in U.S. and their followers}

Determining which political ideology is extreme and which is not is a very challenging and context-dependent task and usually involves controversies. Any sort of definition leaves considerable room for interpretation. In this paper, we limit our scope to white supremacy and neo-Nazi ideologies as right-wing extremist (RWE) and Antifa as left-wing extremist (LWE) ideology in the current U.S. political arena. We identified 25 white supremacy and neo-Nazi groups that have active Twitter accounts by consulting the Southern Poverty Law Center website (SPLC 2018) and list their names and Twitter handles in Table A1 in the Appendix section. For Antifa groups, we relied on manual search on Twitter to identify popular official and local chapters of the movement and came up with a list 16 verified Antifa accounts. The verification was performed through cross-checking our list with those listed at blocktogether.org, a crowdsourcing web application intended to share a list of fake Antifa accounts.

To obtain more validated Antifa accounts so that we have equal number of left- and right-wing extremist seed accounts, we collected 4527 friends (i.e. those who are being followed) and 5,639,256 friends of friends of our initial 16 Antifa accounts and built their friendship network. We perform $k$-core decomposition on the friendship network to obtain the main core of it. The $k$-core of a graph is formally defined as the maximal subgraph with nodes of at least degree $k$. The main core is the non-empty graph with maximum value of $k$ and can be used to identify the most influential nodes of a given network (e.g. Kitsak et al. [55]).

Previous research also used $k$-core decomposition to characterize the efficiency of the spread of information (Conover et al. [21]) or disinformation (Shao et al. [82]). From the obtained main core, we take 9 users who have the highest degrees and manually check their Twitter pages to make sure they are associated to Antifa. The manual process includes looking for either mentioning of "Antifa" in the name, Twitter handle, or bio description of the group, or high volume sharing of content posted by other known Antifa pages (more than half of the recent 50 tweets), plus the number of followers (only include those with more than 5000 followers). Finally, we add these obtained influential users to our list of 16 LWE extremist accounts to form our final list of 25 Antifa accounts and report their names and Twitter handles in Table A2 in the Appendix section. We call these two sets of LWE 
Table 1 List of the five most liberal and conservative U.S. senators according to their 2018 DW-NOMINATE scores

\begin{tabular}{ll}
\hline Liberals & Tammy Baldwin, Mazie Hirono, Edward Markey, Bernie Sanders, Elizabeth Warren \\
Conservatives & Ted Cruz, Jeff Flake, Mike Lee, Rand Paul, Ben Sasse
\end{tabular}

Table 2 Data summary

\begin{tabular}{|c|c|c|c|c|}
\hline & LW & RW & LWE & RWE \\
\hline No. of seed accounts & 5 & 5 & 25 & 25 \\
\hline No. of followers & $12,296,381$ & $6,308,557$ & 248,108 & 329,471 \\
\hline No. of unique followers & $8,489,101$ & $3,849,008$ & 143,759 & 173,211 \\
\hline No. of unique followers after preprocessing & 28,249 & 28,669 & 61,196 & 57,163 \\
\hline No. of unique preprocessed followers after bot exclusion & 26,594 & 27,245 & 59,709 & 55,363 \\
\hline No. of followers who follow at least 3 seed accounts & 9400 & 12,034 & 7665 & 10,983 \\
\hline No. of qualified followers & 9119 & 11,808 & 7314 & 10,609 \\
\hline Randomly sampled from qualified followers & 5000 & 5000 & 5000 & 5000 \\
\hline
\end{tabular}

and RWE extremist individual/organization lists as "seed accounts". We get the followers of these seed accounts, and from those users who passed the preprocessing step (see Sect. 3.3), we consider a follower as a supporter or sympathizer of an extreme political ideology if s/he follows at least three of the corresponding accounts from our seed accounts.

\subsection{Control groups}

To test our hypotheses, we compare the psychological profile of political extremists with qualified followers of the top five most liberal and conservative U.S. Senators according to their 2018 DW-NOMINATE score (Poole and Rosenthal [74]). Table 1 demonstrates the list of Senator names in each political category. We perform all preprocessing steps mentioned in Sect. 3.3 on followers of these Senators. In addition, we exclude mutual followers between each pair of political ideologies. Finally, we only consider users who follow at least three Senators from each category.

\subsection{Preprocessing of followers}

We crawled all followers of the seed accounts (Table 2). In case of liberals or left-wing (LW) and conservatives or right-wing (RW) followers, after collecting the total number of unique followers (Table 2), we uniformly sample 10,000 followers at random from each of the seed accounts (i.e. 50,000 LW and 50,000 RW in total) and perform the rest of the preprocessing and analysis on these samples. We only keep those user IDs that their language is English, are from the U.S., and are not "verified". We impose the "not verified" constraint to exclude potential journalists, news anchors, and celebrities. We further exclude users who mentioned "journalist" or "RT $\neq$ Endorsement" in their bio. We also exclude mutual followers between political groups (i.e. those who follow at least one seed account from at least two political groups). After these preprocessing steps, we use botometer (Davis et al. [26], Varol et al. [98]) to identify bots. Using more than a thousand features including friends, tweet content, tweet sentiment, network properties, and temporal patterns, botometer provides two scores between zero and one for English speaking users and universal users, where zero indicates the highest classifier confidence for a human, and one for a bot. Any score in-between means that the classifier is not certain about the account and we have to make a decision. We use the 0.7 threshold for the English speaker score and exclude all users with scores beyond that from our data. Next, to make sure that the 
followers of the seed accounts are really affiliated with the political groups, following Barberá [12], we only consider those followers who follow at least three of the seed accounts from each political group.

Finally, to control for any potential differences between followers of those seed accounts that belong to groups and those that belong to individuals, we removed all followers who were only following individual RWE accounts. In case of LWE seed accounts, there is only one individual account. This results in $9400 \mathrm{LW}, 12,034 \mathrm{RW}, 7665 \mathrm{LWE}$, and 10,983 RWE affiliated Twitter users (Table 2). We collected up to 3200 tweets of these users and analyze their timestamps. We limit our analysis to those tweets which have posted in a prior three months of the date of our data collection, which was on March 15, 2018. We exclude those users who have not posted in this time period or those whose oldest available tweet in our data set is after December 15, 2017 and call the remaining users as "qualified users" in Table 2. We make the latter restriction to make sure that the users' tweets are representative of their temporal changes over the course of three months. Finally, we uniformly take 5000 users at random from the qualified users and estimate their text-based psychological and moral variables (see Sects. 3.5 and 3.6 on how to estimate the psychological and moral indicators from tweets). The summary of the users at each step of the data collection process is listed in Table 2.

\subsection{Preprocessing of tweets}

Before we procced to estimating the psychological and moral profile of extremists and non-extremists, we need to perform some preprocessing on our text data. First, we convert all tweet texts to lowercase and remove all URLs, user mentions, and punctuations from the text. We further remove retweets from our corpus of data since retweets are not the original posts of the authors and should not be considered as emotional expressions of the users. To control for temporal variations, we only consider those tweets which have been posted within a prior three months.

\subsection{Inferring and validating psychological indicators}

A rich body of research has shown the relationship between linguistic usage and emotion (Pennebaker et al. [71]). We use well-validated Linguistic Inquiry and Word Count (LIWC) lexicon to measure the set of psychological variables mentioned in H1-H3. LIWC uses frequency percentages to gauge individuals' preferences regarding specific "function" words as well as "content" words that are chosen to convey semantic information. We constructed psychological language profiles using the LIWC2015 lexicon (Pennebaker et al. [69]). To measure certainty (H1), we consider the certainty words list from the cognitive processes category. Examples of the certainty words and word-phrases include "always", "never", and "certain". To quantify the anxiety (H2) and happiness (H3), we use the anxiety, positive emotion, and negative emotion words lists from the affective processes category. Examples of the affective processes words and word-phrases include "love", "nice", and "sweet" for positive emotion, "hurt", "ugly", and "nasty" for negative emotion, and "worried" and "fearful" for anxiety. We use these affective and cognitive processes word lists to count the number of usages across all the tweets in a user's Twitter "timeline" expressed as a proportion of the user's total word count. For a review of using Twitter data in health and well-being research see Sinnenberg et al. [85].

Although LIWC have been validated and used in many contexts, to the best of our knowledge, it has never been used on text originated from political extremists. Therefore, 
Table 3 Correlation statistics between LIWC-generated and hand-coded psychological scores for 100 political extremist-written tweets

\begin{tabular}{lllll}
\hline Statistics & Anxiety & Certainty & $\begin{array}{l}\text { Negative } \\
\text { emotion }\end{array}$ & $\begin{array}{l}\text { Positive } \\
\text { emotion }\end{array}$ \\
\hline Coefficient & 0.31 & 0.28 & 0.38 & 0.32 \\
$p$ value & 0.02 & 0.03 & 0.003 & 0.01 \\
\hline
\end{tabular}

the question remains whether or not it can properly estimate the text-based psychological profile of political extremists. Therefore, before using LIWC, we need to validate its performance on extremists' tweets. To accomplish the validation task, we uniformly sample 100 tweets at random from the corpus of extremists-generated tweets. Then, the first author evaluated the extent to which each of the sampled tweets communicated each of the four psychological constructs (i.e. anxiety, certainty, negative and positive emotion) using a 7-point Likert-type scale. Next, we run LIWC on tweets and compute the ratio of hits associated with each of the four psychological measures. Finally, we compute the Pearson correlation coefficient between the hand-coded and LIWC-generated scores and report the results in Table 3. As can be seen, there are significant and strong positive correlations between the hand-coded and LIWC-generated scores across all four psychological constructs, which indicates that the LIWC dictionary words and terms for anxiety, certainty, positive emotion, and negative emotion are sufficiently robust to detect the corresponding psychological constructs in tweets published by American left- and right-wing political extremists identified in this study.

\subsection{Inferring moral foundations}

Graham et al. [38] developed Moral Foundations Dictionary (MFD), which contains word lists associated with each of the five moral foundations introduced in the MFT. Examples of the words include "safe", "peace", and "endanger" for harm avoidance and care, "fair", "equal" and "disproportion" for fairness and reciprocity, "together", "nation", and "traitor" for in-group and loyalty, "obey", "law", "tradition", and "illegal" for authority and respect, and "piety", "innocent", and "trashy" for purity and sanctity. Graham et al. [38] applied the MFD on sermons in text form and the results were consistent with MFT. Using MFD to analyze 12 years of news content related to stem cell research, Clifford and Jerit [20] found consistent results with MFT with respect to harm avoidance and purity moral foundations. They further showed that word lists related to the other three foundations rarely appeared in their dataset through content analysis of a small number of randomly selected articles.

Similar to LIWC dictionary, we could not find any previous study that has validated the application of MFD in the political extremism context. Therefore, we take the same procedure as described above in the Sect. 3.5 and report the validity statistics in Table 4. The results show significant and strong correlations between hand-coded and MFD-generated scores across all five moral foundations.

\subsection{Confounding covariates}

There are many variables that might contribute to the text-based psychological indicators of Twitter users. Hence, without controlling for common causes, our results would be confounded. In the case of language analysis of Twitter users through word-count approach, an analyst should select variables that might affect the distribution of the words among individuals. Table 5 lists a set of covariates which we measured for use as covariates of 
Table 4 Correlation statistics between MFD-generated and hand-coded moral scores for 100 political extremist-written tweets

\begin{tabular}{llllll}
\hline Statistics & Authority & Fairness & $\begin{array}{l}\text { Harm } \\
\text { avoidance/ } \\
\text { care }\end{array}$ & $\begin{array}{l}\text { In-group } \\
\text { loyalty }\end{array}$ & Purity \\
\hline Coefficient & 0.29 & 0.51 & 0.46 & 0.28 & 0.57 \\
$p$ value & 0.035 & 0.0000 & 0.0002 & 0.05 & 0.0000 \\
\hline
\end{tabular}

Table 5 List of covariates

\begin{tabular}{ll}
\hline Name & Description \\
\hline Tweet count & Number of tweets in the past three months \\
Mention count & Number of users mentions in the past three months \\
Retweet count & Number of retweets in the past three months \\
Activity frequency & Average inter-event days between user's activity \\
Followers count & Number of extant followers \\
Friends count & Number of extant friends \\
Favorites counts & Total number of times a user favorited others' post \\
Tenure & Days since creation of an account \\
Profile picture & Weather a user has a profile picture \\
Tweet topics & Variables indicating the ratio of users' tweets about a given topic \\
\hline
\end{tabular}

psychological language of different groups. For example, one could hypothesize that users who published more tweets are more likely to get matched with LIWC and MFD dictionaries, and thus, get higher scores. To better demonstrate the covariate imbalance across the groups, the distribution of the covariates listed in Table 5 (except for topic) are plotted in Fig. A1 in the Appendix section.

One important latent confounding variable that could impose bias on our results is topics of the tweets. That is, since different political groups might disproportionally talk more/less about certain topics compared to the others, some words are more/less likely to be used by members of those particular political groups. If this is the case, and those frequently used words are associated with some of the LIWC or MFD categories, that would cast doubts on our results, because the potential observed psychological differences between political groups are then driven in part by those highly topic-related words, not the political ideology or extremity of the users in those political groups. For example, it would be hard to talk about gun control issues without using certain terms that might be found in LIWC and MFD dictionaries, including terms such as "control", "own", and "power". Therefore, we should control for these topics before comparing text-based psychological/moral profiles of different political users. When we control for topics, in fact we are conditioning out the average level of psychological/moral constructs in those topics.

Latent Dirichlet Allocation (LDA) is a popular method for topic modeling on text data. However, standard LDA would not work well for tweets because they are short, and a single tweet usually talks about only one topic. Therefore, unlike LDA which yields a distribution of various topics for a document, we use a Twitter-LDA method (Zhao et al. [103]), which assigns each tweet to only one topic. Since we are interested in controlling for general topics (e.g. elections, gun control, hate speech, etc.), not events and stories, we set the number of topics at 20 and iterations at 1000 and used Twitter-LDA's default settings (Zhao et al. [103]) to estimate the topics of tweets. The word distribution of the topics along with their suggested names are listed in Table A3 in the Appendix section. 


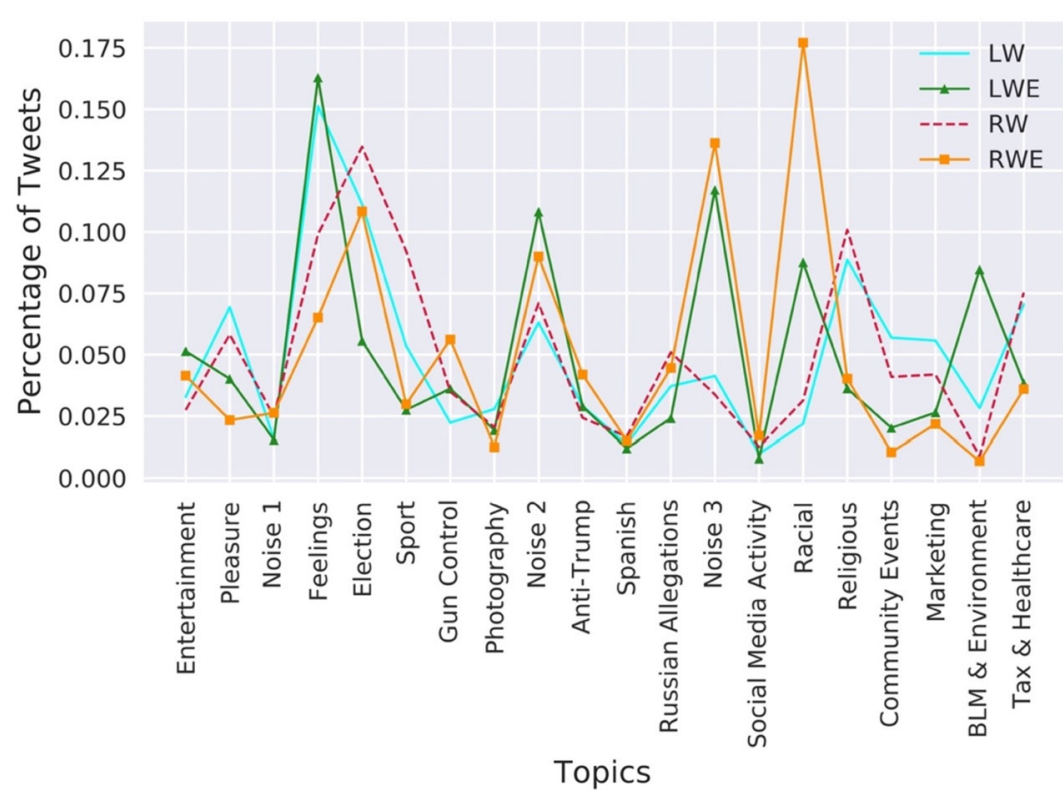

Figure 1 Distribution of Twitter-LDA-generated topics across various political groups. The number of topics is set to 20. While the frequency of occurrence of some topics are similar among the groups (e.g. entertainment and photography), there are topics that their frequency differences between groups are high (e.g. sport and racial). We control for a topic if it is semantically meaningful (i.e. it is not a noisy outcome of the LDA) and does not overlap too much with the word categories of interest in LIWC and MFD. As a result, we remove Noise 1, 2, \& 3, Feelings, and Pleasure topics and controlled for the remaining 15 topics

Figure 1 shows the distribution of topics across the four different political groups. While the frequency differences of some topics are small across the groups (e.g. entertainment, photography, and social media activity), there are topics that their frequency differences between the four groups of users are large (e.g. election, sport, racial, religious, community events, and black lives matter (BLM) and environment). These results further emphasize the importance of adjusting for topics in our analysis. However, not all topics are eligible or required to be adjusted for. We should control for a topic if it:

1. Is semantically meaningful (i.e. it is not noisy outcome of the LDA);

2. Does not overlap too much with the word categories of interest in LIWC and MFD.

As a result, we should not control for "Noise 1", "Noise 2", and "Noise 3" topics simply because they are not representative of semantically meaningful topics. Furthermore, we should not adjust for "Pleasure" and "Feelings" because they overlap too much with the positive emotion category of LIWC.

\subsection{Covariates adjustment}

Since the users are not randomly assigned to each of the four groups, our observational study of their social media activities would suffer from selection bias. Therefore, we should identify confounding variables and control for them so that we can characterize mean differences that are more likely to be about the link between political orientation, political extremity, and text-based psychological indicators of psychological and moral constructs. In addition, we have a multi-valued treatments experiment with four levels, each representing a different group of political users. Thus, reducing covariate imbalance between 
them is not a trivial task, since most of the existing approaches and tools are designed for binary treatments.

According to Rosenbaum and Rubin [80], if we have relevant information on a set of covariates $X$, and the potential outcomes are independent of the treatment, then we can estimate an unbiased estimator using only the propensity score and the observed outcome. The propensity score is the conditional probability of being treated at some point in covariates space, $P(T=1 \mid X)$, where $T$ is the treatment status, with $T=1$ meaning treated and $T=0$ meaning nontreated. Here, the four group labels (i.e. LW, RW, LWE, and RWE) are used as the treatment indicator.

However, there are two main difficulties in using propensity scores: (1) even a slight misspecification in the estimation of propensity scores can result in getting a biased estimate (e.g. Smith and Todd [86], Kang and Schafer [54]); and (2) balancing covariates between more than two groups of subjects is not trivial. To tackle these issues, Imai and Ratkovic [46] introduced Covariate Balancing Propensity Score (CBPS) methodology, which estimates the propensity scores for each observation while optimizing the covariate balance. It also generalizes well to multi-valued treatments. Once the propensity scores are computed, they can be used for weighting, matching, regression, stratification, or a combination of them (Imai and Ratkovic [46]). See Imbens [47] and Stuart [89] for extensive review of propensity score methods.

In this paper, we use the inverse of the estimated propensity scores as weights to create a balanced sample of treated and control observations. The method is known as Inverse Probability Weighting. An important advantage of using weighting over other possible approaches is that we do not lose any of our subjects. Let $T_{i, j}$ be an indicator variable denoting whether user $i$ has received $j$ th treatment (i.e. whether it belongs to LWE, LW, RW, or RWE), and $e_{i, j}$ denotes the propensity score associated with the user $i$ receiving treatment $j$. Then, for multi-valued treatments, the weights can be obtained from Eq. (1):

$$
w_{i j}=\sum_{j=0}^{J-1} \frac{T_{i, j}}{e_{i, j}} .
$$

Figure 2 compares the covariate imbalance measured as difference in means between our four treatment groups (LW is coded as group 1, LWE as 2, RW as 3, and RWE as 4) before and after weighting. Each point on the plot is a covariate and each boxplot represents the median, min and max, upper and lower quartiles of the covariates for each contrast. Comparing the covariate imbalance before (the upper panel) and after (the lower panel) weighting in Fig. 1 shows that applying the weights obtained from the CBPS method is significantly reduced the covariates imbalance, measured as absolute difference of standardized means, across all four treatment groups.

\section{Results}

We use Analysis of Variance (ANOVA) to test for correlation of political orientation and political extremity with certainty, anxiety, positive and negative emotions, and the five moral foundations mentioned in the Moral Foundation Theory (MFT) across conservatives, liberals, left-wing extremists, and right-wing extremists. Then we use Tukey's HSD test for performing post hoc multiple pairwise-comparison between means of the groups. Finally, to make sure that the results are not driven by sample size, for each of the psycho- 


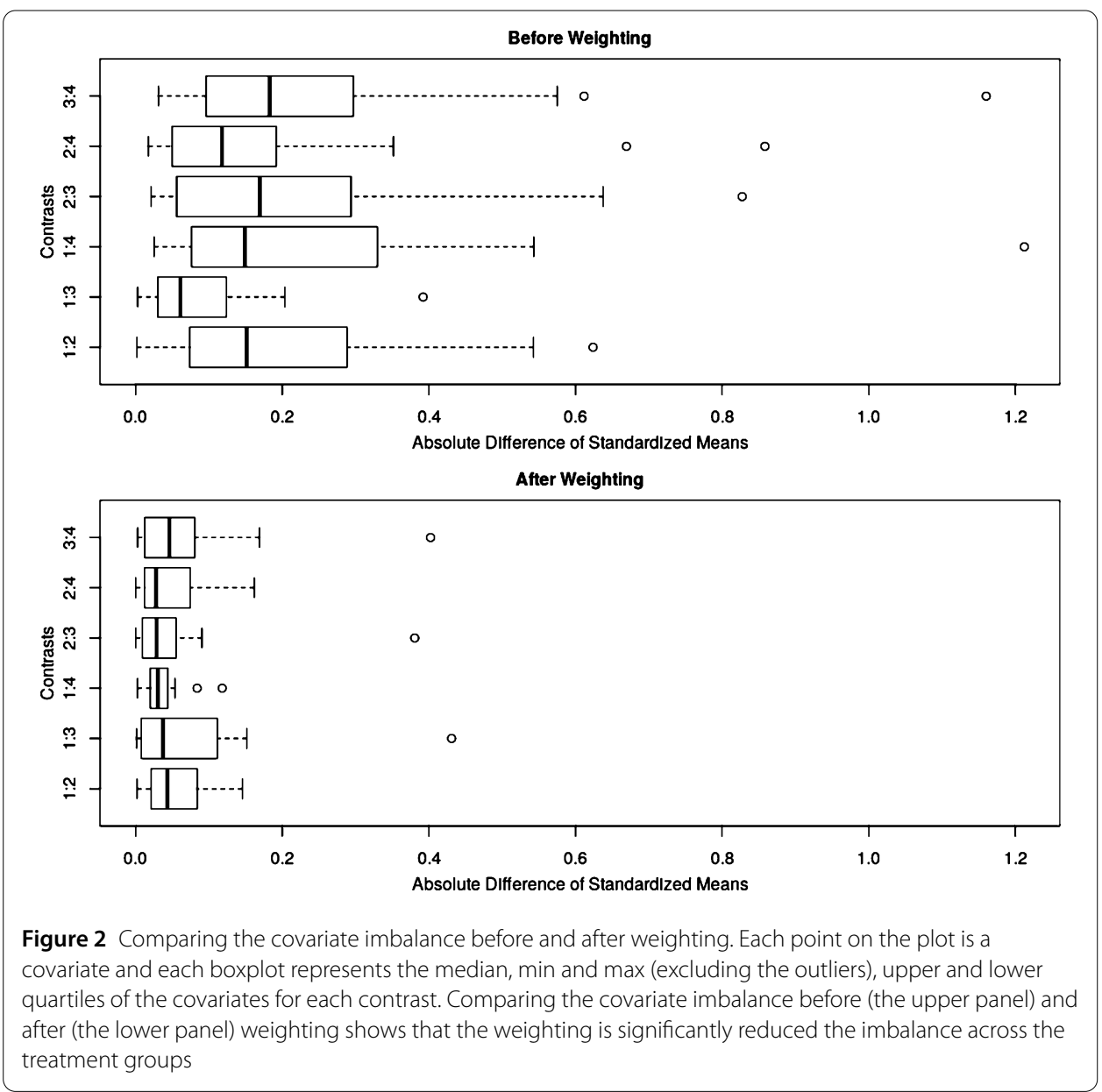

logical and moral variables, we uniformly sample 25 percent of the users from each group at random and perform the Tukey's HSD test and report the results in the Appendix section.

\subsection{Certainty}

In this section, we use ANOVA and Tukey's HSD test to assess whether political extremists have higher/lower text-based indicators of certainty than non-extremists ( $H 1 a$ and $H 1 b$ ), and left-wing extremists have lower text-based indicators of certainty than rightwing extremists $(H 1 c)$. A one-way ANOVA is conducted to test for correlation of political orientation and political extremity with text-based indicators of certainty across various political groups and the results are reported in Table 6 . The results show that there is a significant correlation between political extremity and text-based indicators of certainty at the 0.05 level $(F(1,1)=5.44, p=0.02)$. However, the effect size is not significant when we use a Bonferroni adjusted alpha level of 0.0055 (0.05/9). Therefore, we cannot reject the null hypothesis against $H 1 a$.

Tukey's HSD test results in Table 7 show that none of the mean differences across the four groups are significant. Among them, we can see that although the mean score for text-based indicators of certainty of right-wing extremists is higher than left-wing extremists (Mean Difference $=0.0001, C I=[-0.0007,0.0009], p=0.98$ ), the mean difference is not significant at the 0.0055 Bonferroni adjusted alpha level. Therefore, we cannot reject 
Table 6 ANOVA results to test for correlation of political orientation and extremity with text-based indicators of certainty

\begin{tabular}{lccccc}
\hline & $\begin{array}{c}\text { Degree of } \\
\text { freedom }\end{array}$ & Sum of square & Mean square & $F$ value & $\operatorname{Pr}(>F)$ \\
\hline Political orientation & 1 & 0.00000004 & 0.00000004 & 1.08 & 0.299 \\
Political extremity & 1 & 0.00000019 & 0.00000019 & 5.44 & 0.020 \\
Residuals & 19,997 & 0.00060811 & 0.00000003 & - & - \\
\hline
\end{tabular}

Significance codes: $<0.001:^{\prime * * * ', 0.001: ~}{ }^{* * *}, 0.0055:^{*}$ !

Table 7 Multi-group mean comparisons of certainty using Tukey's HSD test

\begin{tabular}{|c|c|c|c|c|}
\hline & \multirow{2}{*}{$\begin{array}{l}\text { Mean } \\
\text { difference }\end{array}$} & \multicolumn{2}{|c|}{ 95\% Confidence interval } & \multirow{2}{*}{$\begin{array}{l}\text { Adjusted } \\
\text { P-value }\end{array}$} \\
\hline & & $\begin{array}{l}\text { Lower } \\
\text { bound }\end{array}$ & $\begin{array}{l}\text { Upper } \\
\text { bound }\end{array}$ & \\
\hline Iwe-Iw & -0.0004 & -0.0012 & 0.0004 & 0.5723 \\
\hline rw-lw & 0.0003 & -0.0005 & 0.0011 & 0.7805 \\
\hline rwe-Iw & -0.0003 & -0.0011 & 0.0005 & 0.835 \\
\hline rw-lwe & 0.0007 & -0.0001 & 0.0015 & 0.1112 \\
\hline rwe-lwe & 0.0001 & -0.0007 & 0.0009 & 0.9759 \\
\hline rwe-rw & -0.0005 & -0.0013 & 0.0002 & 0.2863 \\
\hline
\end{tabular}

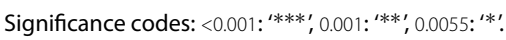

Table 8 ANOVA results to test for correlation of effect of political orientation and extremity with text-based indicators of anxiety

\begin{tabular}{lccccc}
\hline & $\begin{array}{c}\text { Degree of } \\
\text { freedom }\end{array}$ & Sum of square & Mean square & Fvalue & $\operatorname{Pr}(>F)$ \\
\hline Political orientation & 1 & 0.00000028 & 0.00000028 & 38.41 & $<0.001^{* * *}$ \\
Political extremity & 1 & 0.00000001 & 0.00000001 & 0.81 & 0.367 \\
Residuals & 19,997 & 0.00012607 & 0.00000001 & - & - \\
\hline
\end{tabular}

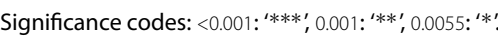

the null hypothesis against $H 1 c$. The results from the smaller sample size when we only consider 25 percent of the data show pretty much the similar pattern (Table A4 in the Appendix). The only exception is that the mean difference between right-wing extremists and liberals becomes significant $(p=0.001)$. Taken together, the results of this section suggest that, there are no significantly differences in how often liberals, conservatives, left-wing extremists (LWE), and right-wing extremists (RWE) use language indicative of certainty in their tweets.

\subsection{Anxiety}

The ANOVA results to test our hypotheses on whether right-wing extremists show higher language indicative of anxiety $(H 2 a)$, or lower than others $(H 2 b)$ are reported in Table 8. The results show that controlling for political extremity, political orientation is a reliable predictor of the text-based indicators of anxiety $(F(1,1)=38.41, p<0.001)$, even if we use the Bonferroni adjusted alpha level of 0.0055 . However, the relationship between political extremity and language-based anxiety scores across the four political groups is nonsignificant $(F(1,1)=0.81, p=0.367)$.

The results of the post-hoc multi-group pairwise comparisons of the means using the Tukey's HSD test are reported in Table 9. Right-wing extremists (RWE) score lower on text-based indicators of anxiety than left-wing extremists (Mean Difference $=$ 
Table 9 Multi-group mean comparisons of anxiety using Tukey's HSD test

\begin{tabular}{|c|c|c|c|c|}
\hline & \multirow{2}{*}{$\begin{array}{l}\text { Mean } \\
\text { difference }\end{array}$} & \multicolumn{2}{|c|}{ 95\% Confidence interval } & \multirow{2}{*}{$\begin{array}{l}\text { Adjusted } \\
\text { P-value }\end{array}$} \\
\hline & & $\begin{array}{l}\text { Lower } \\
\text { bound }\end{array}$ & $\begin{array}{l}\text { Upper } \\
\text { bound }\end{array}$ & \\
\hline Iwe-Iw & 0.0005 & 0.0002 & 0.0009 & $<0.001^{* * *}$ \\
\hline rw-Iw & -0.0001 & -0.0005 & 0.0002 & 0.73 \\
\hline rwe-Iw & -0.0005 & -0.0008 & -0.0001 & $<0.001^{* * *}$ \\
\hline rw-lwe & -0.0007 & -0.001 & -0.0003 & $<0.001^{* * *}$ \\
\hline rwe-lwe & -0.001 & -0.0014 & -0.0006 & $<0.001^{* * *}$ \\
\hline rwe-rw & -0.0003 & -0.0007 & 0 & 0.07 \\
\hline
\end{tabular}

Significance codes: $<0.001:^{\prime 2 * * \prime, ~} 0.0011^{\prime * *}, 0.0055:^{\prime *}$ '

Table 10 ANOVA results to test for correlation of political orientation and extremity with positive and negative emotions

\begin{tabular}{|c|c|c|c|c|c|}
\hline & $\begin{array}{l}\text { Degree of } \\
\text { freedom }\end{array}$ & Sum of square & Mean square & $F$ value & $\operatorname{Pr}(>F)$ \\
\hline \multicolumn{6}{|l|}{ Positive emotion: } \\
\hline Political orientation & 1 & 0.000003 & 0.0000026 & 11.24 & $0.001^{* *}$ \\
\hline Political extremity & 1 & 0.000017 & 0.0000167 & 73.11 & $<0.001^{* * *}$ \\
\hline Residuals & 19,997 & 0.003962 & 0.0000002 & - & - \\
\hline \multicolumn{6}{|l|}{ Negative emotion: } \\
\hline Political orientation & 1 & 0.000001 & 0.0000012 & 12.08 & $0.001^{* *}$ \\
\hline Political extremity & 1 & 0.000007 & 0.0000074 & 73.17 & $<0.001^{* * *}$ \\
\hline Residuals & 19,997 & 0.001757 & 0.0000001 & - & - \\
\hline
\end{tabular}

Significance codes: $<0.001:^{\prime * * * \prime,} 0.001:^{\prime * * \prime}, 0.0055:^{\prime * \prime}$

$-0.001, C I=[-0.0014,-0.0006], p<0.001$ ), liberals (Mean Difference $=-0.0005, C I=$ $[-0.0008,-0.0001], p<0.001$ ), and conservatives (Mean Difference $=-0.0003, C I=$ $[-0.0007,0], p=0.07)$. Except for the comparison with conservatives, all of the mean differences are significant at the Bonferroni adjusted alpha levels of 0.0055. The results from $25 \%$ sample size are in general agreement with this finding (Table A5 in the Appendix). The only exception is that although the mean difference between right-wing extremists and liberals is significant at 0.05 level $(p=0.03)$, it is nonsignificant when we use the Bonferroni adjusted alpha level of 0.0055 . Therefore, we should reject $H 2 a$. However, we cannot reject the null hypothesis against $H 2 b$. Nevertheless, the results suggest that rightwing extremists score significantly lower on text-based indicators of anxiety than liberals and left-wing extremists.

\subsection{Happiness}

In this section, we test for hypotheses regarding mean differences of text-based indicators of positive and negative emotions in a multi-group study of liberals, conservatives, leftwing extremists, and right-wing extremists. The ANOVA results (Table 10) show that both political orientation and political extremity are significant predictors of the text-based indicators of positive (Political Orientation: $F(1,1)=11.24, p=0.001$; Political Extremity: $F(1,1)=73.11, p<0.001$ ) and negative emotions (Political Orientation: $F(1,1)=12.08$, $p=0.001$; Political Extremity: $F(1,1)=73.17, p<0.001)$, even if we use the Bonferroni adjusted alpha level of 0.0055 .

Now that the predictors are found to be significant, we turn to the results of post-hoc comparisons using the Tukey's HSD test in Table 11. We can see that, while conservatives 
Table 11 Multi-group mean comparisons of positive and negative emotions using Tukey's HSD test

\begin{tabular}{|c|c|c|c|c|}
\hline & \multirow{2}{*}{$\begin{array}{l}\text { Mean } \\
\text { difference }\end{array}$} & \multicolumn{2}{|c|}{ 95\% Confidence interval } & \multirow{2}{*}{$\begin{array}{l}\text { Adjusted } \\
\text { P-values }\end{array}$} \\
\hline & & $\begin{array}{l}\text { Lower } \\
\text { bound }\end{array}$ & $\begin{array}{l}\text { Upper } \\
\text { bound }\end{array}$ & \\
\hline \multicolumn{5}{|c|}{ Positive emotion: } \\
\hline Iwe-Iw & -0.0065 & -0.0084 & -0.0047 & $<0.001^{* * *}$ \\
\hline rw-lw & -0.0004 & -0.0023 & 0.0014 & 0.9381 \\
\hline rwe-Iw & -0.0027 & -0.0046 & -0.0008 & $0.0016^{*}$ \\
\hline rw-lwe & 0.0061 & 0.0043 & 0.008 & $<0.001^{* * *}$ \\
\hline rwe-lwe & 0.0038 & 0.0019 & 0.0058 & $<0.001^{* * *}$ \\
\hline rwe-rw & -0.0023 & -0.0042 & -0.0004 & 0.0104 \\
\hline \multicolumn{5}{|c|}{ Negative emotion: } \\
\hline Iwe-Iw & 0.0038 & 0.0026 & 0.005 & $<0.001^{* * *}$ \\
\hline rw-lw & -0.0003 & -0.0015 & 0.0008 & 0.9026 \\
\hline rwe-lw & 0.0018 & 0.0006 & 0.003 & $0.0009^{* * *}$ \\
\hline rw-lwe & -0.0041 & -0.0053 & -0.003 & $<0.001^{* * *}$ \\
\hline rwe-lwe & -0.002 & -0.0032 & -0.0008 & $0.0001^{* * *}$ \\
\hline rwe-rw & 0.0021 & 0.0009 & 0.0033 & $<0.001^{* * *}$ \\
\hline
\end{tabular}

Significance codes: $<0.001:^{\prime * * * \prime,} 0.001:^{\prime * *}, 0.0055:^{\prime *}$ !

use lower number of words indicative of positive emotion (Mean Difference $=-0.0004$, $C I=[-0.0023,0.0014], p=0.93)$, and negative emotion (Mean Difference $=-0.0003, C I=$ $[-0.0015,0.0008], p=0.90)$ than liberals, none of the mean differences is significant at the 0.0055 Bonferroni adjusted level. The results from a smaller sample size where we only consider 25 percent of the data show similar pattern (Table A6 in the Appendix). Therefore, we should reject both hypotheses $\mathrm{H3a}$ (conservatives show higher positive emotion and lower negative emotion than liberals) and $H 3 d$ (liberals show higher positive emotion and lower negative emotion than conservatives).

Post-hoc comparisons using the Tukey's HSD test indicate that, when comparing leftwing extremists (LWE) and liberals (LW), LWE score lower on text-based indicators of positive emotion (Mean Difference $=-0.0065, C I=[-0.0084,-0.0047], p<0.001$ ) and higher on negative emotion than liberals (Mean Difference $=0.0038, C I=[0.0026,0.005]$, $p<0.001$ ), and both mean differences are significant at the 0.0055 Bonferroni adjusted alpha level. Comparing right-wing extremists (RWE) and conservatives (RW) reveals the same pattern, with the exception that the mean difference in positive emotion is not significant at the Bonferroni adjusted alpha level of 0.0055 (Mean Difference $=-0.0023$, $C I=[-0.0042,-0.0004], p=0.01)$. Therefore, the results support $H 3 e$ and reject $H 3 b$ for left-wing extremists. Tukey's HSD results from the $25 \%$ sample size analysis show similar pattern (Table A6 in the Appendix). Therefore, we should also reject $H 3 b$ for RWE, but we cannot reject null hypothesis against $H 3 e$ for RWE.

The results of Table 11 further show that, when comparing right-wing extremists and left-wing extremists (i.e. $H 3 c$ vs. $H 3 f$ ), right-wing extremists score higher on text-based indicators of positive emotion (Mean Difference $=0.0038, C I=[0.0019,0.0058], p<0.001$ ) and lower on negative emotion (Mean Difference $=-0.002, C I=[-0.0032,-0.0008], p<$ 0.001). Both mean differences are significant at the Bonferroni adjusted alpha level of 0.0055. Comparing LWE and RWE in Table A6 in the Appendix, where only considered $25 \%$ of the data, demonstrate the same findings. Therefore, the results support $H 3 c$ and reject $H 3 f$.

Taken together, the results suggest that any observed differences in text-based indicators of positive and negative emotions between liberals and conservatives are not statistically 
significant. However, in general, extremists use less language indicative of positive emotion and higher of negative emotions compared to non-extremists. The only exception is between RWE and RW in positive emotion, which if use a conservative significance threshold, the difference is not significant. Finally, RWE have higher text-based positive emotion and lower text-based negative scores compared to LWE.

\subsection{Moral foundations theory}

In the following five sub-sections, we present results on testing hypotheses about the relationship between political orientation/extremism and the Moral Foundations Theory (MFT). The general form of hypotheses we are investigating here are whether or not:

(a) MFT's predictions of conservatives speaking more enthusiastically than liberals about obedience to authority, ingroup loyalty, and purity, and liberals speaking more enthusiastically about fairness and harm avoidance can be generalized to the political extremists; and

(b) MFT's prediction of elevated moral foundations among extremists can be empirically supported.

\subsubsection{Fairness}

We use ANOVA to test for the correlation of political orientation and political extremity with text-based measures of fairness and report the results in Table 12. The results show that political orientation is a significant predictor of the language usage of words indicative of appreciation of fairness $(F(1,1)=16.41, p<0.001)$, even if we use the Bonferroni adjusted alpha level of 0.0055 . In case of political extremity, although it is a significant predictor of the outcome variable at the 0.05 level $(F(1,1)=5.21, p=0.022)$, it becomes a nonsignificant one at the Bonferroni adjusted significance level of 0.0055 .

Post hoc comparisons of mean differences using the Tukey's HSD test (Table 13) show that although conservatives score lower on text-based indicators of fairness (which is in agreement with MFT), the mean difference is not significant at the Bonferroni adjusted al-

Table 12 ANOVA results to test for correlation of political orientation and extremity with text-based indicators of fairness

\begin{tabular}{lccccc}
\hline & $\begin{array}{c}\text { Degree of } \\
\text { freedom }\end{array}$ & Sum of square & Mean square & $F$ value & $\operatorname{Pr}(>F)$ \\
\hline Political orientation & 1 & 0.00000003 & 0.000000030 & 16.41 & $<0.001^{* * *}$ \\
Political extremity & 1 & 0.00000001 & 0.000000010 & 5.21 & 0.022 \\
Residuals & 19,997 & 0.00003219 & 0.000000002 & - & - \\
\hline
\end{tabular}

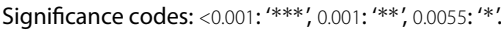

Table 13 Multi-group mean comparisons of fairness using Tukey's HSD test

\begin{tabular}{|c|c|c|c|c|}
\hline & \multirow{2}{*}{$\begin{array}{l}\text { Mean } \\
\text { difference }\end{array}$} & \multicolumn{2}{|c|}{ 95\% Confidence interval } & \multirow{2}{*}{$\begin{array}{l}\text { Adjusted } \\
\text { P-value }\end{array}$} \\
\hline & & $\begin{array}{l}\text { Lower } \\
\text { bound }\end{array}$ & $\begin{array}{l}\text { Upper } \\
\text { bound }\end{array}$ & \\
\hline Iwe-Iw & 0.0001 & -0.0001 & 0.0002 & 0.8738 \\
\hline rw-Iw & -0.0001 & -0.0002 & 0.0002 & 0.9749 \\
\hline rwe-lw & -0.0003 & -0.0005 & -0.0001 & $0.0003^{* * *}$ \\
\hline rw-lwe & -0.0001 & -0.0003 & 0.0001 & 0.6353 \\
\hline rwe-lwe & -0.0003 & -0.0005 & -0.0002 & $<0.001^{* * *}$ \\
\hline rwe-rw & -0.0003 & -0.0004 & -0.0001 & $0.0014^{*}$ \\
\hline
\end{tabular}

Significance codes: $<0.001:^{\prime * * * \prime, ~} 0.001:^{\prime * *}, 0.0055:^{\prime *}$ ! 
pha level of 0.0055. In addition, the results demonstrate that right-wing extremists (RWE) use significantly lower number of words indicative of fairness than left-wing extremists (LWE) and the mean difference is significant at the Bonferroni adjusted 0.0055 level (Mean Difference $=-0.0003, C I=[-0.0005,-0.00021], p<0.001$ ), which supports H4a. Nonetheless, the results show that although LWE score higher than LW on text-based indicators of fairness, the mean difference is nonsignificant (Mean Difference $=0.0001$, $C I=[-0.0001,0.0002], p=0.87)$. Therefore, we cannot reject the null hypothesis against H4f. Results from performing Tukey's HSD test on the smaller sample size data where we only consider $25 \%$ of the users from each group reveal the same pattern (Table A7 in the Appendix).

In general, the results of this section are in agreement with MFT's predictions of liberals speaking more about fairness than conservatives, and left-wing extremists speaking more about fairness than liberals (i.e. elevated moral foundations among extremists). However, our results do not support the significance of these differences. Nevertheless, the results support our hypothesis of LWE score higher than RWE on text-based indicators of fairness.

\subsubsection{Harm avoidance/care}

The ANOVA results for testing the correlation of political orientation and political extremity with the text-based measures of harm avoidance (care) are demonstrated in Table 14. There is a seemingly significant relationship between political orientation and language usage indicative of harm avoidance across liberals, conservatives, left-wing extremists, and right-wing extremists $(F(1,1)=4.5, p=0.034)$. However, the mean difference is not significant when we use the Bonferroni adjusted alpha level of 0.0055 . On the other hand, political extremity does not seem to significantly correlate with text-based indicators of harm avoidance across the four political groups $(F(1,1)=0.91, p=0.34)$.

We use Tukey's HSD test for a post hoc mean comparisons between the groups ( $\mathrm{Ta}$ ble 15) and results show all pairwise mean differences are nonsignificant (Bonferroni adjusted alpha $=0.0055)$. Same pattern is true when we only consider 25 percent of the data (Table A8 in the Appendix). More particularly, we can see that, contrary to MFT's predictions, conservatives score lower than liberals on text-based indicators of harm avoidance, though, the mean difference is not significant (Mean Difference $=-0.0003$, $C I=[-0.0008,0.0002], p=0.41)$. In agreement with our hypothesis of left-wing extremists (LWE) expressing more language indicative of harm avoidance than right-wing extremists (i.e. H4b), the results of Table 15 show that RWE on average score 0.0004 unit lower than LWE on harm avoidance language-based construct, however, the mean difference is not significant (Mean Difference $=-0.0004, C I=[-0.0009,0.0001], p=0.2$ ). In addition,

Table 14 ANOVA results to test for correlation of political orientation and extremity with text-based indicators of harm avoidance

\begin{tabular}{lccccc}
\hline & $\begin{array}{l}\text { Degree of } \\
\text { freedom }\end{array}$ & Sum of square & Mean square & $F$ value & $\operatorname{Pr}(>F)$ \\
\hline Political orientation & 1 & 0.00000011 & 0.00000011 & 4.50 & 0.034 \\
Political extremity & 1 & 0.00000002 & 0.00000002 & 0.91 & 0.34 \\
Residuals & 19,997 & 0.00043226 & 0.00000002 & - & - \\
\hline
\end{tabular}

Significance codes: <0.001: '***', 0.001: '**', 0.0055: '*'. 
Table 15 Multi-group mean comparisons of harm avoidance using Tukey's HSD test

\begin{tabular}{|c|c|c|c|c|}
\hline & \multirow{2}{*}{$\begin{array}{l}\text { Mean } \\
\text { difference }\end{array}$} & \multicolumn{2}{|c|}{ 95\% Confidence interval } & \multirow{2}{*}{$\begin{array}{l}\text { Adjusted } \\
\text { P-value }\end{array}$} \\
\hline & & $\begin{array}{l}\text { Lower } \\
\text { bound }\end{array}$ & $\begin{array}{l}\text { Upper } \\
\text { bound }\end{array}$ & \\
\hline Iwe-Iw & -0.0001 & -0.0006 & 0.0004 & 0.9453 \\
\hline rw-lw & -0.0003 & -0.0008 & 0.0002 & 0.4058 \\
\hline rwe-lw & -0.0005 & -0.0011 & 0 & 0.0576 \\
\hline rw-lwe & -0.0002 & -0.0007 & 0.0003 & 0.7547 \\
\hline rwe-lwe & -0.0004 & -0.0009 & 0.0001 & 0.1985 \\
\hline rwe-rw & -0.0002 & -0.0007 & 0.0003 & 0.7327 \\
\hline
\end{tabular}

Significance codes: $<0.001:^{\prime * * * \prime, ~} 0.001:^{\prime * *}, 0.0055:^{\prime *}$ !

Table 16 ANOVA results to test for correlation of political orientation and extremity with text-based indicators of ingroup loyalty

\begin{tabular}{lccccc}
\hline & $\begin{array}{c}\text { Degree of } \\
\text { freedom }\end{array}$ & Sum of square & Mean square & $F$ value & $\operatorname{Pr}(>F)$ \\
\hline Political orientation & 1 & 0.00000004 & 0.00000004 & 3.651 & 0.056 \\
Political extremity & 1 & 0.00000006 & 0.00000006 & 6.056 & $0.014^{*}$ \\
Residuals & 19,997 & 0.00018303 & 0.00000001 & - & - \\
\hline
\end{tabular}

Significance codes: $<0.001:^{\prime * * * \prime, ~} 0.001:^{\prime * * \prime,}, 0.0055:^{\prime *}$ !

contrary to MFT's prediction, left-wing extremists score lower than liberal on language indicators of harm avoidance or care (Mean Difference $=-0.0001, C I=[-0.0006,0.0004]$, $p=0.94$ ), though, the mean difference is nonsignificant. Therefore, we should reject $H 4 g$.

Taken together, the results of this section discourage the linear extension of MFT's predictions about harm avoidance to the political extremism context. More specifically, the results suggest that, at least when it comes to language usage on Twitter, regardless of political orientation and extremity, individuals are not really different on how much they talk about harm avoidance and care.

\subsubsection{Ingroup loyalty}

The ANOVA results of testing the correlation of political orientation and political extremity with text-based measures of ingroup loyalty across different political groups (Table 16) show a significant relationship with political extremity $(F(1,1)=6.065, p=0.014)$. However, it becomes nonsignificant when we use the Bonferroni adjusted alpha level of 0.0055. Across liberals, conservatives, left- and right-wing extremists, political orientation does not have a significant correlation with text-based expression of ingroup loyalty $(F(1,1)=3.65, p=0.056)$.

To further test our hypotheses of whether right-wing extremists express more language indicative of ingroup loyalty than left-wing extremists (i.e. H4c), and right-wing extremists express more language indicative of ingroup loyalty than conservatives (i.e. $H 4 h$ ), we use post hoc comparisons of means using Tukey's HSD test and report the results in Table 17. First, in agreement with MFT's prediction, the results show that conservatives score higher on text-based indicators of ingroup loyalty than liberals and the mean difference is significant at the Bonferroni adjusted alpha level of 0.0055 (Mean Difference $=0.0005$, $C I=[0.0001,0.001], p=0.0052)$. Second, and contrary to our hypothesis $H 4 c$, it is actually left-wing extremists that score higher than right-wing extremists on text-based indicators of ingroup loyalty (Mean Difference $=-0.0001, C I=[-0.0006,0.0003], p=0.89$ ), 
Table 17 Multi-group mean comparisons of ingroup loyalty using Tukey's HSD test

\begin{tabular}{|c|c|c|c|c|}
\hline & \multirow{2}{*}{$\begin{array}{l}\text { Mean } \\
\text { difference }\end{array}$} & \multicolumn{2}{|c|}{ 95\% Confidence interval } & \multirow{2}{*}{$\begin{array}{l}\text { Adjusted } \\
\text { P-value }\end{array}$} \\
\hline & & $\begin{array}{l}\text { Lower } \\
\text { bound }\end{array}$ & $\begin{array}{l}\text { Upper } \\
\text { bound }\end{array}$ & \\
\hline Iwe-Iw & 0.0001 & -0.0004 & 0.0005 & 0.9834 \\
\hline rW-Iw & 0.0005 & 0.0001 & 0.001 & $0.0052^{*}$ \\
\hline rwe-Iw & -0.0001 & -0.0005 & 0.0004 & 0.9854 \\
\hline rw-Iwe & 0.0005 & 0.0001 & 0.0009 & 0.0195 \\
\hline rwe-Iwe & -0.0001 & -0.0006 & 0.0003 & 0.8949 \\
\hline rwe-rw & -0.0006 & -0.001 & -0.0002 & $0.0022^{*}$ \\
\hline
\end{tabular}

Significance codes: $<0.001:^{\prime * * * ', ~ 0.001: ~}{ }^{\prime * *}, 0.0055$ : $^{\prime *}$.

Table 18 ANOVA results to test for correlation of political orientation and extremity with text-based indicators of obedience to authority

\begin{tabular}{lccccc}
\hline & $\begin{array}{c}\text { Degree of } \\
\text { freedom }\end{array}$ & Sum of square & Mean square & $F$ value & $\operatorname{Pr}(>F)$ \\
\hline Political orientation & 1 & 0.00000089 & 0.00000089 & 56.05 & $<0.001^{* * *}$ \\
Political extremity & 1 & 0.00000004 & 0.00000004 & 2.38 & 0.123 \\
Residuals & 19,997 & 0.00027571 & 0.00000002 & - & - \\
\hline
\end{tabular}

Significance codes: $<0.001:^{\prime * * * \prime,} 0.001:^{\prime * * \prime}, 0.0055:^{\prime * \prime}$

though, the mean difference is not significant. Hence, we should reject $H 4 c$. Third, and contrary to MFT's prediction of elevated ingroup loyalty among right-wing extremists, on average they score lower than conservative on text-based measures of ingroup loyalty, and the mean difference is significant at the Bonferroni adjusted alpha level of 0.0055 (Mean Difference $=-0.0006, C I=[-0.001,-0.0002], p=0.0022)$. Therefore, we reject H4h. Analysis of the smaller sample size (25\% of the data) reveals the same pattern (Table A9 in the Appendix). The only exception is that the mean difference between conservatives and liberals is nonsignificant at the 0.0055 Bonferroni adjusted level $(p=0.025)$.

Generally, while supporting the MFT's claim of conservatives speaking more about ingroup loyalty than liberals, the results of this section cast serious doubts on the extent to which this observation can be generalized to political extremists. In fact, the results suggest that, on average, right-wing extremists have the least expression of ingroup loyalty in their tweets compared to users in the other three political groups.

\subsubsection{Obedience to authority}

The ANOVA results to test hypotheses on the extent to which MFT can be generalized to the political extremists (i.e. $H 4 d$ ), and whether or not MFT's prediction of elevated obedience to authority among the right-wing extremists can be empirically supported (i.e. $\mathrm{H} 4 \mathrm{i}$ ) are reported in Table 18. The result show that political orientation is a significant predictor of text-based indicators of obedience to authority $(F(1,1)=56.05, p<0.001)$, even if we use the Bonferroni adjusted significance level of 0.0055 . However, political extremity's relationship with language usage indicative of obedience to authority is nonsignificant $(F(1,1)=56.05, p=0.12)$.

Post hoc comparisons of the means of groups using the Tukey's HSD test (Table 19) indicates that although conservatives (RW) score higher on text-based measures of obedience to authority, the mean difference is not significant (Mean Difference $=0.0003$, $C I=[-0.0001,0.0007], p=0.18)$. The results further show that right-wing extremists 
Table 19 Multi-group mean comparisons of obedience to authority using Tukey's HSD test

\begin{tabular}{|c|c|c|c|c|}
\hline & \multirow{2}{*}{$\begin{array}{l}\text { Mean } \\
\text { difference }\end{array}$} & \multicolumn{2}{|c|}{ 95\% Confidence interval } & \multirow{2}{*}{$\begin{array}{l}\text { Adjusted } \\
\text { P-value }\end{array}$} \\
\hline & & $\begin{array}{l}\text { Lower } \\
\text { bound }\end{array}$ & $\begin{array}{l}\text { Upper } \\
\text { bound }\end{array}$ & \\
\hline Iwe-Iw & -0.0005 & -0.0009 & -0.0001 & $0.0051^{*}$ \\
\hline rw-lw & 0.0003 & -0.0001 & 0.0007 & 0.18 \\
\hline rwe-Iw & 0.0012 & 0.0008 & 0.0016 & $<0.001^{* * *}$ \\
\hline rw-lwe & 0.0008 & 0.0004 & 0.0012 & $<0.001^{* * *}$ \\
\hline rwe-lwe & 0.0017 & 0.0013 & 0.0021 & $<0.001^{* * *}$ \\
\hline rwe-rw & 0.0009 & 0.0005 & 0.0013 & $<0.001^{* * *}$ \\
\hline
\end{tabular}

Significance codes: $<0.001:^{\prime * * * \prime,} 0.001: * * ;, 0.0055:^{\prime *}$ !

Table 20 ANOVA results to test for correlation of political orientation and extremity with text-based indicators of purity

\begin{tabular}{lcllll}
\hline & $\begin{array}{l}\text { Degree of } \\
\text { freedom }\end{array}$ & Sum of square & Mean square & $F$ value & $\operatorname{Pr}(>F)$ \\
\hline Political orientation & 1 & 0.000000006 & 0.00000006 & 8.54 & $0.003^{*}$ \\
Political extremity & 1 & 0 & 0.000000002 & 0.34 & 0.561 \\
Residuals & 19,997 & 0.0001138 & 0.000000007 & - & - \\
\hline
\end{tabular}

Significance codes: $<0.001:^{\prime * * * \prime,} 0.001:^{\prime * * \prime}, 0.0055:^{\prime *}$.

(RWE) score higher than left-wing extremists (LWE) on text-based measures of obedience to authority (Mean Difference $=0.0017, C I=[0.0013,0.0021], p<0.001$ ). In addition, we can see that RWE use significantly higher language indicative of obedience to authority than conservatives (Mean Difference $=0.0009, C I=[0.0005,0.0013], p<0.001$ ). The latter two mean differences are significant at the 0.0055 Bonferroni adjusted alpha level. Therefore, results support both $H 4 d$ and $H 4 i$. Performing the Tukey's HSD test on the smaller sample size (25\% of the data) shows similar results (Table A10 in the Appendix).

Generally, the results of this section support MFT's prediction about cross-group variations in obedience to authority values. The results suggest that, in terms of the frequency of using text-based signals of obedience to authority, conservatives score higher than liberals, right-wing extremists score higher than left-wing extremists, and right-wing extremists score higher than conservatives. With the exception of mean differences between conservatives and liberals, all other findings are significant at the Bonferroni adjusted alpha level of 0.0055 .

\subsubsection{Purity}

Table 20 presents the ANOVA results of the test for correlation of political orientation and political extremity with text-based measures of purity across liberals, conservatives, left-wing extremist (LWE), and right-wing extremists (RWE). We can see that political orientation is a significant predictor of the text-based measures of purity $(F(1,1)=8.54$, $p=0.003$ ), even at the Bonferroni adjusted alpha level of 0.0055 . However, the political extremity's relationship with the degree to which individuals use language indicative of purity is not significant $(F(1,1)=0.34, p=0.56)$.

The results of the Tukey's HSD post hoc comparisons of means to test the hypotheses of right-wing extremists score higher than left-wing extremists on language-based indicators of purity $(\mathrm{H} 4 \mathrm{e})$ and right-wing extremist score higher than conservatives $(\mathrm{H} 4 \mathrm{j})$ are demonstrated in Table 21. First, in agreement with MFT, we can see that conservatives express more language indicative of purity than liberals (Mean Difference $=0.0003$, 
Table 21 Multi-group mean comparisons of purity using Tukey's HSD test

\begin{tabular}{|c|c|c|c|c|}
\hline & \multirow{2}{*}{$\begin{array}{l}\text { Mean } \\
\text { difference }\end{array}$} & \multicolumn{2}{|c|}{ 95\% Confidence interval } & \multirow{2}{*}{$\begin{array}{l}\text { Adjusted } \\
\text { P-value }\end{array}$} \\
\hline & & $\begin{array}{l}\text { Lower } \\
\text { bound }\end{array}$ & $\begin{array}{l}\text { Upper } \\
\text { bound }\end{array}$ & \\
\hline Iwe-Iw & 0.0001 & -0.0002 & 0.0004 & 0.9193 \\
\hline rw-Iw & 0.0003 & 0.0001 & 0.0006 & 0.0857 \\
\hline rwe-Iw & 0.0003 & 0.0001 & 0.0006 & 0.0645 \\
\hline rw-Iwe & 0.0002 & -0.0001 & 0.0005 & 0.3195 \\
\hline rwe-lwe & 0.0002 & -0.0001 & 0.0005 & 0.2522 \\
\hline rwe-rw & 0.0001 & -0.0003 & 0.0003 & 0.9972 \\
\hline
\end{tabular}

Significance codes: $<0.001:^{\prime * * * \prime}, 0.001:^{\prime * *}, 0.0055:^{\prime *}$.

$C I=[0.0001,0.0006], p=0.086)$, however, the mean difference is nonsignificant at the 0.0055 Bonferroni adjusted level. Second, although right-wing extremists score higher than left-wing extremists on text-based measures of purity, the mean difference is not significant (Mean Difference $=0.0002, C I=[-0.0001,0.0005], p=0.25)$, which in turn, rejects $H 4 e$. Finally, RWE on average score higher than conservatives on text-based indicators of purity, but the mean difference is not significant at the 0.0055 Bonferroni adjusted level (Mean Difference $=0.0001, C I=[-0.0003,0.0003], p=0.997)$. Therefore, we cannot reject the null hypothesis against $H 4 j$. Analysis of the 25 percent sample size reveal pretty much the same pattern (Table A11 in the Appendix): conservatives score higher than liberals and right-wing extremists score higher than left-wing extremists, but both mean differences are nonsignificant. However, in Table A11, right-wing extremists score lower than conservatives, but the mean difference is not significant at the 0.0055 Bonferroni adjusted level $(p=0.16)$.

\subsection{Effect sizes}

Results thus far indicate that there are language differences across liberals, conservatives, left-wing extremists, and right-wing extremists in terms of the proportion of words that appear in the LIWC and MFD dictionaries. But an important question remains that what do these language differences mean psychologically and morally? One way to answer this question is to measure the correlation of these text-based indicators with actual questionnaire-based psychological and moral profiles of individuals. The challenge here is that, as mentioned in the introduction part of this paper, political extremists do not simply volunteer for psychological studies and thus it is hard to find reliable results based on a relatively large sample. Another possible way to find an answer for the validity of the mean differences would be to compare them with text-based psychological and moral indicators of individuals who have some sort of psychological or emotional disorder. However, there are at least two problems associated with this approach. First, although previous applications of the LIWC dictionaries support the significance of this approach in mental health research (e.g. Chung and Pennebaker [19], De Choudhury et al. [28], Coppersmith et al. [22]), the comparability of the groups in terms of other variables of interest or the sufficient/necessary diagnostic criteria for any of the disorders are questionable. Second, we believe these kinds of comparisons are inappropriate because they might inadvertently imply imprecise claims about the population under study.

\section{Discussion}

In this paper, we tested hypotheses about the psychological and moral profiles of political extremists and their differences with partisan users using Twitter data of U.S. left- and 
Table 22 Summary of hypotheses and results

\begin{tabular}{|c|c|c|c|c|}
\hline Variable & Hypothesis & Test & Direction & Significant \\
\hline Certainty & $\begin{array}{l}\text { Extremists }>\text { Non-extremists } \\
\text { Extremists }<\text { Non-extremists } \\
\text { RWE }>\text { LWE }\end{array}$ & $\begin{array}{l}\text { ANOVA } \\
\text { ANOVA } \\
\text { Tukey's HSD }\end{array}$ & $\begin{array}{l}x \\
\checkmark \\
\checkmark\end{array}$ & $\begin{array}{l}x \\
x \\
x\end{array}$ \\
\hline Anxiety & $\begin{array}{l}\text { RWE }>\text { Others } \\
\text { RWE }<\text { Others }\end{array}$ & $\begin{array}{l}\text { Tukey's HSD } \\
\text { Tukey's HSD }\end{array}$ & $\begin{array}{l}x x x \\
\checkmark \checkmark \checkmark\end{array}$ & $\begin{array}{l}x x x \\
\checkmark \checkmark x\end{array}$ \\
\hline Positive emotion & $\begin{array}{l}\text { RW }>\text { LW } \\
\text { RW }<\text { LW } \\
\text { Extremists }>\text { Non-extremists } \\
\text { Extremists }<\text { Non-extremists } \\
\text { RWE }>\text { LWE } \\
\text { RWE }<\text { LWE }\end{array}$ & $\begin{array}{l}\text { Tukey's HSD } \\
\text { Tukey's HSD } \\
\text { ANOVA } \\
\text { ANOVA } \\
\text { Tukey's HSD } \\
\text { Tukey's HSD }\end{array}$ & $\begin{array}{l}x \\
x \\
x \\
y \\
y \\
x\end{array}$ & $\begin{array}{l}x \\
x \\
x \\
y \\
y \\
x\end{array}$ \\
\hline Negative emotion & $\begin{array}{l}\text { RW }>\text { LW } \\
\text { RW }<\text { LW } \\
\text { Extremists }>\text { Non-extremists } \\
\text { Extremists }<\text { Non-extremists } \\
\text { RWE }>\text { LWE } \\
\text { RWE }<\text { LWE }\end{array}$ & $\begin{array}{l}\text { Tukey's HSD } \\
\text { Tukey's HSD } \\
\text { ANOVA } \\
\text { ANOVA } \\
\text { Tukey's HSD } \\
\text { Tukey's HSD }\end{array}$ & $\begin{array}{l}x \\
y \\
y \\
x \\
x \\
y\end{array}$ & $\begin{array}{l}x \\
x \\
y \\
x \\
x \\
y\end{array}$ \\
\hline Fairness & $\begin{array}{l}\mathrm{LWE}>\mathrm{RWE} \\
\mathrm{LWE}>\mathrm{LW}\end{array}$ & $\begin{array}{l}\text { Tukey's HSD } \\
\text { Tukey's HSD }\end{array}$ & $\begin{array}{l}2 \\
2\end{array}$ & $\begin{array}{l}5 \\
x\end{array}$ \\
\hline Harm avoidance & $\begin{array}{l}\text { LWE }>\text { RWE } \\
L W E>L W\end{array}$ & $\begin{array}{l}\text { Tukey's HSD } \\
\text { Tukey's HSD }\end{array}$ & $\begin{array}{l}5 \\
x\end{array}$ & $\begin{array}{l}x \\
x\end{array}$ \\
\hline Obedience to authority & $\begin{array}{l}\text { RWE }>\text { LWE } \\
R W E>R W\end{array}$ & $\begin{array}{l}\text { Tukey's HSD } \\
\text { Tukey's HSD }\end{array}$ & $\begin{array}{l}2 \\
2\end{array}$ & $\begin{array}{l}\checkmark \\
\checkmark\end{array}$ \\
\hline Ingroup loyalty & $\begin{array}{l}\text { RWE }>\text { LWE } \\
\text { RWE }>\text { RW }\end{array}$ & $\begin{array}{l}\text { Tukey's HSD } \\
\text { Tukey's HSD }\end{array}$ & $\begin{array}{l}x \\
x\end{array}$ & $\begin{array}{l}x \\
\checkmark\end{array}$ \\
\hline Purity & $\begin{array}{l}\text { RWE }>\text { LWE } \\
\text { RWE }>\text { RW }\end{array}$ & $\begin{array}{l}\text { Tukey's HSD } \\
\text { Tukey's HSD }\end{array}$ & $\begin{array}{l}\checkmark \\
\checkmark\end{array}$ & $\begin{array}{l}x \\
x\end{array}$ \\
\hline
\end{tabular}

right-wing extremist groups. We summarized all hypotheses and corresponding results in Table 22. The results offer new insights to the moral profile of political extremists while settling some previously debated theories of the psychological appeal of political extremity and orientation. Language analysis of tweets written by 10,000 extremists and 10,000 non-extremist partisan users showed that regardless of political orientation (i.e. left or right), extremists show a lower text-based indicators of positive emotion and higher textbased indicators of negative emotion compared to non-extremists (i.e. liberals and conservatives). In addition, we found that right-wing extremists use more words indicative of positive emotion and lower words indicative of negative emotion compared to left-wing extremists.

In case of anxiety, while left-wing extremists score higher than all other groups on language-based measures of anxiety, right-wing extremists score lower than conservatives. In fact, right-wing extremists express the least language indicative of anxiety among all four studied political groups. In case of certainty, surprisingly, we found no evidence of significant differences between the average text-based indicators of certainty across liberals, conservatives, left-, and right-wing extremists.

Overall, the pattern cast serious doubts on mainstream view of seeing extremists as dogmatic and rigid individuals with high attitude certainty and anxiety. Instead, it lends support to theories such as the System Justification Theory (Jost and Hunyady [52]) which argue that ideology in general and political extremity in particular operate as a buffering factor for mental distress. For example, the observations that right-wingers express more positive emotion and less negative emotion words than left-wingers are analogous to pre- 
vious findings that showed conservatives are happier than liberals (e.g. Napier and Jost [66]), which can be explained by the idea that conservative system-justifying ideologies serve as a palliative function (Jost and Banaji [50]). In addition, the results resonate with Sidanius's [84] view of characterizing political extremists as sophisticated individuals who can manage the societal pressure of being deviant and have higher uncertainty tolerance. However, another explanation could simply be the fact that having a Republican president makes right-wing users more satisfied with the policies and therefore they are more likely to use words with positive emotion connotations. One can conduct a longitudinal study and compare the psychological indicators of the users analyzed in this paper with their corresponding psychological indicators in the time of Obama's presidency.

With respect to the Moral Foundations Theory (MFT), although our results are in general agreement with the MFT, they demand to carefully investigate the role of political extremists to understand how much of the observed differences between liberals and conservatives are driven by the individuals at both (extreme) ends of the political spectrum. Our results support the MFT's prediction of constatives scoring higher than liberals on obedience to authority, ingroup loyalty, and purity and lower on fairness, however, only the ingroup loyalty mean difference was significant. The results, however, do not support the MFT's prediction of liberals scoring higher than conservatives on text-based indicators of harm avoidance and care. In fact, our results show quite the opposite direction, though, the mean difference was not significant. This can be attributed, at least in part, to the validity of the Moral Foundations Dictionary (MFD) itself. In our effort to validate the MFD on tweets written by American political extremists, we found the least correlation and the corresponding $p$-value between the hand-coded tweets and MFD-generated scores for the harm avoidance category.

Nevertheless, our results show that, with the exception of ingroup loyalty, MFT can be generalized to political extremism context. We found right-wing extremists speak more language indicative of obedience to authority and purity and less language indicative of fairness and harm avoidance than left-wing extremists (the mean differences in fairness and obedience to authority were significant). Surprisingly, in case of ingroup loyalty, the results paint left-wing extremists as the ones who use more words and phrases indicative of ingroup loyalty than right-wing extremists (though the mean difference was nonsignificant).

However, our results were inconclusive with respect to MFT's argument of elevated moral foundation among political extremists. If this was the case, right-wing extremists should have scored higher on text-based measures of obedience to authority, in-group loyalty, and purity compared to conservatives, and left-wing extremists should have scored higher on text-based measures of fairness and harm avoidance than liberals. Among the five moral foundations, our results were consistent with the above prediction in cases of obedience to authority, fairness, and purity. But the only significant effect size was for obedience to authority and the other two mean differences were nonsignificant. On the other hand, the results show the opposite direction for harm avoidance and ingroup loyalty. In fact, it was conservatives who speak more about ingroup loyalty than right-wing extremists, and that liberals who speak more about harm avoidance than left-wing extremists.

Our results provide no evidence of a causal relationship between any of the analyzed psychological or moral variables and political extremism. Those who are more emotional/moral may be more susceptible to extremist appeals or those with extremist views 
may express themselves with more emotion/morality, or both. For instance, becoming an extremist could lead one to express negative emotion, in part because almost no one shares your views, rather than (or in addition to) being a source of its appeal. Furthermore, there may be psychological differences between extremists who express their political opinions and emotions on Twitter and those who do not, or those who do not even use social media. Nor do these results rule out the alternative theory that material deprivation and political oppression encourage extremist views and emotional agitation. Moreover, although tweets can reflect voluntary expressions of support for certain groups or ideas, users are not free from desirability or self-presentations biases. For instance, they might choose not to publicly express their real opinions and emotions because they afraid to get suspended by Twitter or isolated by their followers. We also cannot rule out any geographical bias imposed on our results (see Alizadeh et al. [5] for a review of the effect of spatial proximity on peer interaction and opinion dynamics) since we do not have access to the location of the users.

We also have no evidence about extremist or violent behavior. Our analysis is focused on those who follow and support non-violent extremists and is therefore limited to the psychological profiles associated with attraction to extremist views. We do not have data for the followers of violent extremist groups or behavioral measures of their activities offline. The results are nevertheless useful in providing evidence about the psychological and moral profiles of those who are attracted to extremist views.

\section{Appendix}

Table A1 List of white nationalist and neo-nazi groups in the U.S. who have active Twitter account on December 2017

\begin{tabular}{rlll}
\hline No. & Group name & Twitter screen name & Ideological type \\
\hline 1 & American Freedom Party & American3rdP & White nationalist \\
2 & American Front & MWAmericanFront & Neo-nazi \\
3 & American Nazi Party & ANP14 & Neo-nazi \\
4 & American Renaissance & AmRenaissance & White nationalist \\
5 & Aryan Brotherhood & Aryan_Brother & Neo-nazi \\
6 & Brad Dean Griffin & Occdissent & White nationalist \\
7 & Counter Current Publishing (Greg Johnson) & NewRightAmerica & White nationalism \\
8 & David Duke & DrDavidDuke & White nationalist \\
9 & David Irving & IrvingBooks & Neo-nazi \\
10 & Hal Turner & RealHalTurner & White nationalist \\
11 & James Edward & JamesEdwardTPC & White nationalist \\
12 & Jared Taylor & jartaylor & White nationalist \\
13 & Jason Kessler & TheMadDimension & White nationalist \\
14 & John de Nugent & johndenugentESA & White nationalist \\
15 & Kevin Strom & kevin_a_strom & Neo-nazi \\
16 & Kyle Bristow & KyleBristow & White nationalist \\
17 & Nathan Benjamin Damigo & NathanDamigo & White nationalist \\
18 & National Socialist Movement & nsm88 & Neo-nazi \\
19 & Richard Bertrand Spencer & RichardBSpencer & White nationalist \\
20 & Texas Nationalist Movement & TexasNatMov & White nationalist \\
21 & The Political Cesspool & TPCRadio & White nationalist \\
22 & The Revolutionary Conservative & TRevolutionaryC & White nationalist \\
23 & Thomas Robb & ThomasRobb & White nationalist \\
24 & Traditionalist Worker Party & TradWorker & Neo-nazi \\
25 & VDARE Foundation & vdare & White nationalist \\
\hline
\end{tabular}


Table A2 List of Antifa groups in U.S. who have active Twitter account on December 2017

\begin{tabular}{rll}
\hline No. & Name & Twitter screen name \\
\hline 1 & AK Press & AKPressDistro \\
2 & Anarcho Anon & AnarchoAnon \\
3 & Anonymous Calm & Anonymous_Ca1m \\
4 & Antifa News & antifa_news1 \\
5 & Antifa Philadelphia & PhillyANTIFA \\
6 & Antifa Seven Hills & ash_antifa \\
7 & Atlanta Antifascists & afainatl \\
8 & Antifascist Action Phoenix & AFAPHX \\
9 & Berkeley Antifa & berkeleyantifa \\
10 & Eugene Antifa & eugeneantifa \\
11 & HubCityAntifa & HubCityAntifa \\
12 & It's Going Down & IGD_News \\
13 & Natalie Solidarity & Constantnatalie \\
14 & Natalie Solidarity & COnst4ntN4t4l13 \\
15 & Nebraska Antifa & antifa_ne \\
16 & New York City Antifa & NYCAntifa \\
17 & Occupy Oakland & OccupyOakland \\
18 & Official Antifa & OfficialAntifa \\
19 & Orlando Antifa & OrlandoAntifa \\
20 & Rocky Mountain Antifa & RckyMtnAntifa \\
21 & Rose City Antifa & RoseCityAntifa \\
22 & Sam Tyler & RadNewsMedia \\
23 & TORCH & TorchAntifa \\
24 & Unicorn Riot & UR_Ninja \\
25 & Wolftrap AF & WolftrapAF \\
\hline & &
\end{tabular}

Table A3 List of the words in each tweet-LDA estimated topics along with their suggested potential names

\begin{tabular}{|c|c|c|}
\hline Topic & Top words and hashtags in the topic & $\begin{array}{l}\text { Suggested } \\
\text { name }\end{array}$ \\
\hline 0 & $\begin{array}{l}\text { video, playlist, added, music, book, nowplaying, song, love, star, movie, } \\
\text { soundcloud, listening, episode, youtube, film }\end{array}$ & Entertainment \\
\hline 1 & $\begin{array}{l}\text { day, good, great, love, time, back, happy, home, morning, drinking, night, today, } \\
\text { food, house, snow, ice, park, coffee }\end{array}$ & Pleasure \\
\hline 2 & $\begin{array}{l}\text { latest, libraries, out, daily, today, scorpio, learn, adoption, old, stories, domestic, } \\
\text { short, editor, thoughts, letter }\end{array}$ & Latest News \\
\hline 3 & good, time, love, people, make, feel, day, life, pretty, night, work, today, thought & Feelings \\
\hline 4 & $\begin{array}{l}\text { trump, people, president, obama, hillary, vote, good, stop, news, time, fake, } \\
\text { america, make, gop, country, hope, media, party, dems, white }\end{array}$ & Election \\
\hline 5 & game, good, team, stats, football, team, great, win, play, week, season, nfl & Sport \\
\hline 6 & $\begin{array}{l}\text { police, man, people, gun, killed, school, black, protest, cops, shooting, white, } \\
\text { muslim, military, shot, arrested, illegal }\end{array}$ & Gun Control \\
\hline 7 & $\begin{array}{l}\text { photo, check, love, gameinsight, art, happy, size, follow, day, photoset, added, } \\
\text { photography, ipad, persiscope, beautiful }\end{array}$ & Photography \\
\hline 8 & $\begin{array}{l}\text { people, good, read, make, twitter, tweet, thing, thought, pretty, bad, feel, } \\
\text { understand, time, article, agree, find }\end{array}$ & NA (Noise) \\
\hline 9 & $\begin{array}{l}\text { maga, trump, resist, theresistamce, vote, impeachtrump, trumpshutdown, } \\
\text { trumprussia, releasethememo, trumptrain, tcot, fakenews, feelthebern, } \\
\text { notmypresident }\end{array}$ & Anti-Trump \\
\hline 10 & les, des, du, trump, pour, qui, président, pas, une, sur, dans & Spanish \\
\hline 11 & $\begin{array}{l}\text { trump, obama, donald, clinton, president, news, house, white, fbi, russia, video, } \\
\text { gop, campaign, election, state, russian, bill, tcot, senate, cnn, mueller }\end{array}$ & $\begin{array}{l}\text { Russian- } \\
\text { Related } \\
\text { Allegations }\end{array}$ \\
\hline 12 & $\begin{array}{l}\text { lol, fuck, shit, good, people, love, white, Imao, twitter, guy, ass, make, real, hell, } \\
\text { damn, god, holly, dude }\end{array}$ & NA (Noise) \\
\hline
\end{tabular}


Table A3 (Continued)

\begin{tabular}{|c|c|c|}
\hline Topic & Top words and hashtags in the topic & $\begin{array}{l}\text { Suggested } \\
\text { name }\end{array}$ \\
\hline 13 & $\begin{array}{l}\text { people, follower, unfollowed, automatically, unfollowers, stats, person, today, } \\
\text { week, past, found, gained, miles, latest, lost, day }\end{array}$ & $\begin{array}{l}\text { Social Media } \\
\text { Activity }\end{array}$ \\
\hline 14 & $\begin{array}{l}\text { people, white, black, women, hate, men, world, country, america, war, jews, } \\
\text { whites, stop, political, racist, race, trump, support, free }\end{array}$ & Racial \\
\hline 15 & $\begin{array}{l}\text { love, happy, good, god, hope, day, birthday, life, bless, people, jesus, miss, glad, } \\
\text { hear }\end{array}$ & Religious \\
\hline 16 & $\begin{array}{l}\text { great, check, win, join, today, day, free, enter, tonight, live, support, badge, school, } \\
\text { chance, meeting, event, tomorrow, excited, happy, community, students }\end{array}$ & $\begin{array}{l}\text { Community } \\
\text { Events }\end{array}$ \\
\hline 17 & $\begin{array}{l}\text { media, great, learn, twitter, social, data, business, account, check, google, } \\
\text { marketing, free, health, policy, violates, temporarily }\end{array}$ & $\begin{array}{l}\text { Social Media } \\
\text { Policies and } \\
\text { Marketing }\end{array}$ \\
\hline 18 & $\begin{array}{l}\text { police, support, climate, people, join, black, city, stop, march, protest, solidarity, } \\
\text { water, rights, fight, justice, community, rally, blacklivesmatter, stand }\end{array}$ & $\begin{array}{l}\text { Minorities } \\
\text { Rights and } \\
\text { Environment }\end{array}$ \\
\hline 19 & $\begin{array}{l}\text { tax, bill, health, vote, pay, state, illegal, care, senate, gop, congress, government, } \\
\text { money, million, healthcare, plan, jobs, law }\end{array}$ & $\begin{array}{l}\text { Tax and } \\
\text { Healthcare }\end{array}$ \\
\hline
\end{tabular}

Table A4 Multi-group mean comparisons of certainty in 25\% sample size data using Tukey's HSD test

\begin{tabular}{|c|c|c|c|c|}
\hline & \multirow{2}{*}{$\begin{array}{l}\text { Mean } \\
\text { difference }\end{array}$} & \multicolumn{2}{|c|}{ 95\% Confidence interval } & \multirow{2}{*}{$\begin{array}{l}\text { Adjusted } \\
\text { P-value }\end{array}$} \\
\hline & & $\begin{array}{l}\text { Lower } \\
\text { bound }\end{array}$ & $\begin{array}{l}\text { Upper } \\
\text { bound }\end{array}$ & \\
\hline Iwe-Iw & -0.0006 & -0.002 & 0.001 & 0.79 \\
\hline rw-lw & -0.0004 & -0.002 & 0.0011 & 0.91 \\
\hline rwe-lw & -0.002 & -0.004 & -0.0007 & $0.001^{*}$ \\
\hline rw-lwe & 0.0002 & -0.001 & 0.0017 & 0.99 \\
\hline rwe-Iwe & -0.002 & -0.003 & -0.0002 & 0.02 \\
\hline rwe-rw & -0.002 & -0.003 & -0.0004 & 0.009 \\
\hline
\end{tabular}

Significance codes: $<0.001:^{\prime * * * \prime, ~} 0.001:^{\prime * * \prime, ~} 0.0055:^{* *}$.

Table A5 Multi-group mean comparisons of anxiety in 25\% sample size data using Tukey's HSD test

\begin{tabular}{|c|c|c|c|c|}
\hline & \multirow{2}{*}{$\begin{array}{l}\text { Mean } \\
\text { difference }\end{array}$} & \multicolumn{2}{|c|}{ 95\% Confidence interval } & \multirow{2}{*}{$\begin{array}{l}\text { Adjusted } \\
\text { P-value }\end{array}$} \\
\hline & & $\begin{array}{l}\text { Lower } \\
\text { bound }\end{array}$ & $\begin{array}{l}\text { Upper } \\
\text { bound }\end{array}$ & \\
\hline Iwe-Iw & -0.0002 & -0.0006 & 0.0004 & 0.95 \\
\hline rw-Iw & -0.0005 & -0.001 & 0.0001 & 0.07 \\
\hline rwe-Iw & -0.0005 & -0.001 & -0.00007 & 0.03 \\
\hline rw-lwe & -0.0004 & -0.0009 & 0.0001 & 0.021 \\
\hline rwe-Iwe & -0.0008 & -0.001 & -0.0002 & $0.001^{*}$ \\
\hline rwe-rw & -0.0001 & -0.0006 & 0.00001 & 0.98 \\
\hline
\end{tabular}

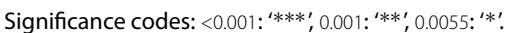


Table A6 Multi-group mean comparisons of positive and negative emotions in $25 \%$ sample size data using Tukey's HSD test

\begin{tabular}{lcccc}
\hline & $\begin{array}{l}\text { Mean } \\
\text { difference }\end{array}$ & \multicolumn{2}{c}{$95 \%$ Confidence interval } & \multirow{2}{*}{$\begin{array}{c}\text { Adjusted } \\
\text { P-values }\end{array}$} \\
\cline { 3 - 4 } & & $\begin{array}{l}\text { Lower } \\
\text { bound }\end{array}$ & $\begin{array}{c}\text { Upper } \\
\text { bound }\end{array}$ & \\
\hline Positive emotion: & & & & \\
Iwe-Iw & -0.0069 & -0.01 & -0.0035 & $<0.001^{* * *}$ \\
rw-Iw & -0.002 & -0.005 & 0.0016 & 0.59 \\
rwe-Iw & 0.002 & -0.0014 & 0.005 & 0.42 \\
rw-Iwe & 0.005 & 0.002 & 0.0085 & $0.0002^{* * *}$ \\
rwe-Iwe & 0.009 & 0.0055 & 0.012 & $<0.001^{* * *}$ \\
rwe-rw & 0.0037 & 0.0003 & 0.007 & 0.02 \\
Negative emotion & & & & \\
Iwe-Iw & 0.0028 & 0.00046 & 0.005 & 0.01 \\
rw-Iw & -0.0007 & -0.003 & 0.001 & 0.84 \\
rwe-Iw & 0.0019 & 0.0005 & 0.004 & 0.16 \\
rw-Iwe & -0.0035 & -0.0058 & -0.001 & $0.0003^{* * *}$ \\
rwe-Iwe & -0.001 & -0.0032 & -0.00004 & $0.001^{* *}$ \\
rwe-rw & 0.0027 & 0.0003 & 0.005 & $0.0051^{*}$ \\
\hline
\end{tabular}

Significance codes: <0.001: '***', $0.001:^{\prime * * \prime, ~} 0.0055$ : $^{* \prime}$.

Table A7 Multi-group mean comparisons of fairness in 25\% sample size data using Tukey's HSD test

\begin{tabular}{|c|c|c|c|c|}
\hline & \multirow{2}{*}{$\begin{array}{l}\text { Mean } \\
\text { difference }\end{array}$} & \multicolumn{2}{|c|}{ 95\% Confidence interval } & \multirow{2}{*}{$\begin{array}{l}\text { Adjusted } \\
\text { P-value }\end{array}$} \\
\hline & & $\begin{array}{l}\text { Lower } \\
\text { bound }\end{array}$ & $\begin{array}{l}\text { Upper } \\
\text { bound }\end{array}$ & \\
\hline Iwe-Iw & 0.0001 & -0.0003 & 0.0004 & 0.96 \\
\hline rw-Iw & -0.0002 & -0.0005 & 0.0002 & 0.60 \\
\hline rwe-lw & -0.0004 & -0.0008 & -0.00002 & 0.03 \\
\hline rw-lwe & -0.0003 & -0.0006 & 0.0001 & 0.29 \\
\hline rwe-lwe & -0.0005 & -0.0008 & -0.00009 & $0.0046^{*}$ \\
\hline rwe-rw & -0.0003 & -0.0006 & -0.00015 & 0.41 \\
\hline
\end{tabular}

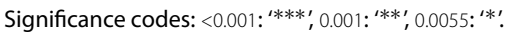

Table A8 Multi-group mean comparisons of harm avoidance in 25\% sample size data using Tukey's HSD test

\begin{tabular}{|c|c|c|c|c|}
\hline & \multirow{2}{*}{$\begin{array}{l}\text { Mean } \\
\text { difference }\end{array}$} & \multicolumn{2}{|c|}{ 95\% Confidence interval } & \multirow{2}{*}{$\begin{array}{l}\text { Adjusted } \\
\text { P-value }\end{array}$} \\
\hline & & $\begin{array}{l}\text { Lower } \\
\text { bound }\end{array}$ & $\begin{array}{l}\text { Upper } \\
\text { bound }\end{array}$ & \\
\hline Iwe-Iw & -0.0001 & -0.001 & -0.0005 & 0.03 \\
\hline rw-Iw & -0.001 & -0.002 & -0.0004 & 0.007 \\
\hline rwe-Iw & -0.001 & -0.0018 & -0.0002 & 0.008 \\
\hline rw-lwe & -0.0003 & -0.0011 & 0.0005 & 0.71 \\
\hline rwe-lwe & -0.0002 & -0.001 & 0.0006 & 0.95 \\
\hline rwe-rw & 0.0001 & -0.0006 & 0.0009 & 0.96 \\
\hline
\end{tabular}

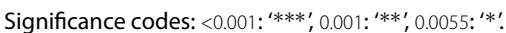


Table A9 Multi-group mean comparisons of ingroup loyalty in 25\% sample size data using Tukey's HSD test

\begin{tabular}{lllcl}
\hline & $\begin{array}{l}\text { Mean } \\
\text { difference }\end{array}$ & \multicolumn{2}{l}{$95 \%$ Confidence interval } & \multirow{2}{*}{$\begin{array}{l}\text { Adjusted } \\
\text { P-value }\end{array}$} \\
\cline { 3 - 4 } & & $\begin{array}{l}\text { Lower } \\
\text { bound }\end{array}$ & $\begin{array}{l}\text { Upper } \\
\text { bound }\end{array}$ & \\
\hline Iwe-Iw & -0.0006 & -0.001 & 0.00008 & 0.11 \\
rw-Iw & 0.0007 & -0.0014 & 0.00007 & 0.025 \\
rwe-Iw & -0.0007 & -0.0014 & -0.00002 & 0.041 \\
rw-Iwe & -0.00052 & -0.0008 & 0.0005 & 0.94 \\
rwe-Iwe & -0.0002 & -0.0008 & 0.0006 & 0.97 \\
rwe-rw & -0.00003 & -0.0006 & 0.0007 & 0.59 \\
\hline
\end{tabular}

Significance codes: $<0.001:^{\prime * * * \prime,} 0.001:^{\prime * *}, 0.0055:^{\prime *}$.

Table A10 Multi-group mean comparisons of obedience to authority in 25\% sample size data using Tukey's HSD test

\begin{tabular}{lcccc}
\hline & $\begin{array}{l}\text { Mean } \\
\text { difference }\end{array}$ & \multicolumn{2}{c}{$95 \%$ Confidence interval } & \multirow{2}{*}{$\begin{array}{l}\text { Adjusted } \\
\text { P-value }\end{array}$} \\
\cline { 3 - 4 } & $\begin{array}{l}\text { Lower } \\
\text { bound }\end{array}$ & $\begin{array}{l}\text { Upper } \\
\text { bound }\end{array}$ & \\
\hline Iwe-Iw & -0.0001 & -0.0007 & 0.0005 & 0.99 \\
rw-Iw & 0.0002 & -0.0001 & 0.0004 & 0.26 \\
rwe-Iw & 0.005 & 0.004 & 0.0056 & $<0.001^{* * *}$ \\
rw-Iwe & -0.0004 & -0.001 & 0.0002 & 0.41 \\
rwe-Iwe & 0.005 & 0.004 & 0.0057 & $<0.001^{* * *}$ \\
rwe-rw & 0.0054 & 0.0047 & 0.006 & $<0.001^{* * *}$ \\
\hline
\end{tabular}

Significance codes: $<0.001:^{\prime * * * \prime, ~} 0.001:^{\prime * * \prime, ~} 0.0055:^{\prime *}$ !

Table A11 Multi-group mean comparisons of purity in 25\% sample size data using Tukey's HSD test

\begin{tabular}{|c|c|c|c|c|}
\hline & \multirow{2}{*}{$\begin{array}{l}\text { Mean } \\
\text { difference }\end{array}$} & \multicolumn{2}{|c|}{ 95\% Confidence interval } & \multirow{2}{*}{$\begin{array}{l}\text { Adjusted } \\
\text { P-value }\end{array}$} \\
\hline & & $\begin{array}{l}\text { Lower } \\
\text { bound }\end{array}$ & $\begin{array}{l}\text { Upper } \\
\text { bound }\end{array}$ & \\
\hline Iwe-Iw & -0.0001 & -0.0006 & 0.0003 & 0.82 \\
\hline rw-Iw & 0.0003 & -0.0002 & 0.0007 & 0.43 \\
\hline rwe-Iw & -0.0001 & -0.0006 & 0.0004 & 0.94 \\
\hline rw-lwe & 0.0004 & -0.00005 & 0.0009 & 0.075 \\
\hline rwe-lwe & 0.0001 & -0.0005 & 0.0005 & 0.99 \\
\hline rwe-rw & -0.0004 & -0.001 & 0.0001 & 0.16 \\
\hline
\end{tabular}

Significance codes: $<0.001$ : $^{* * * *,}, 0.001$ : $^{\prime * * \prime,} 0.0055$ : $^{*}$ ! 
(A)

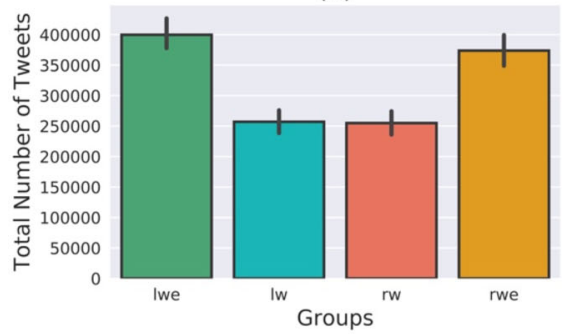

(C)

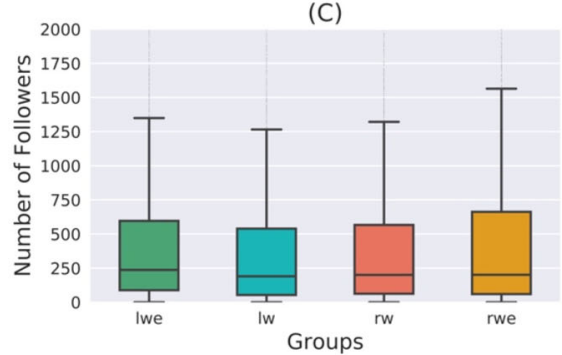

(E)

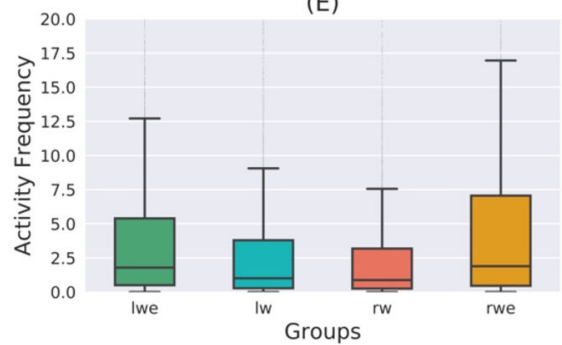

(G)

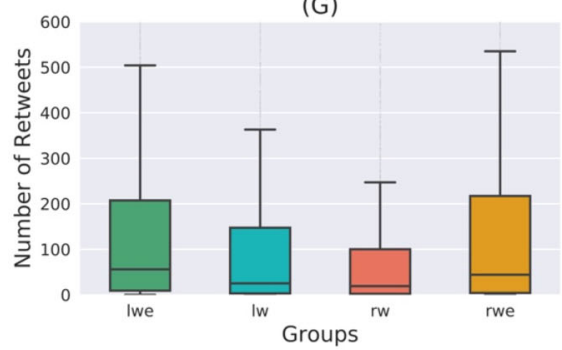

(I)

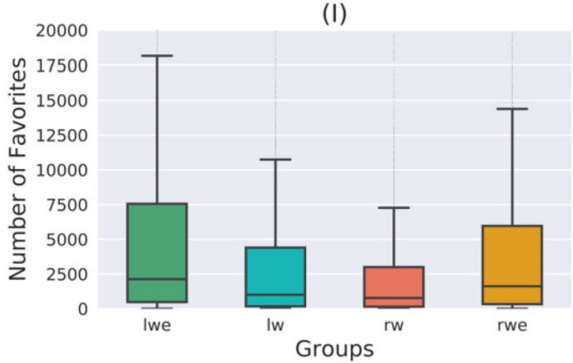

(B)

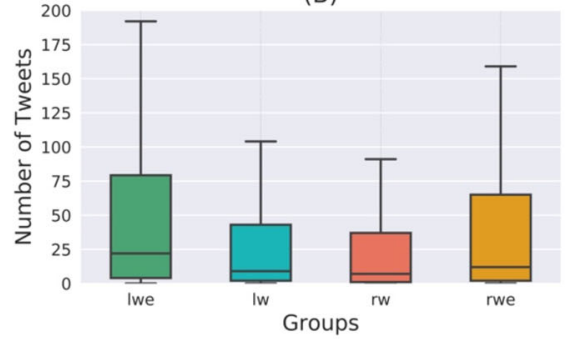

(D)

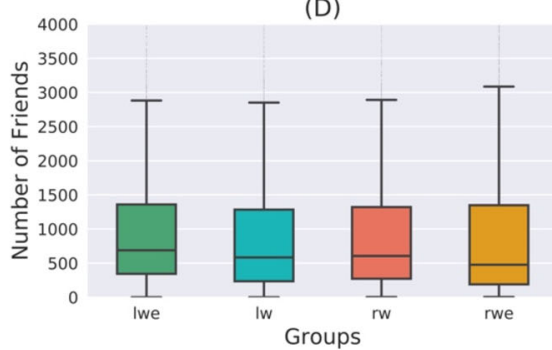

(F)

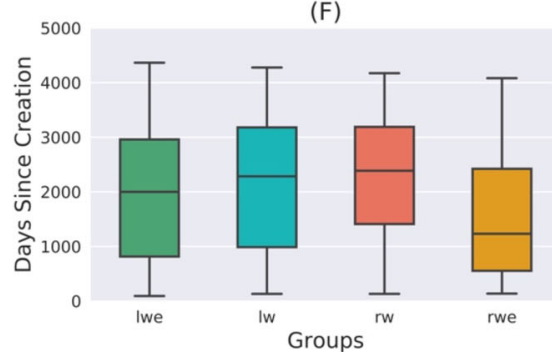

(H)

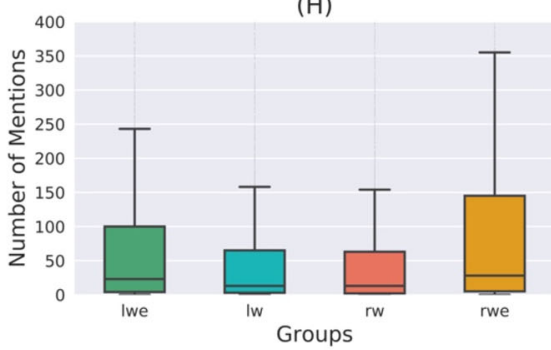

(J)

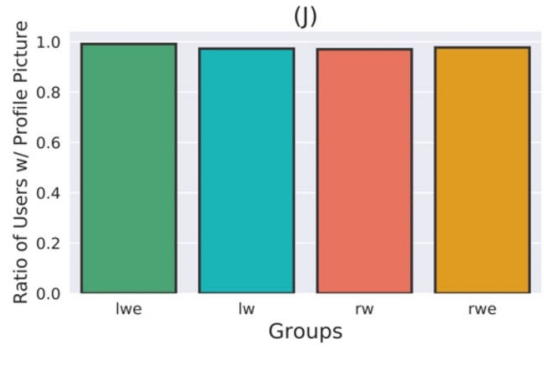

Figure A1 Distribution of the covariates listed in Table 5 (except for topics) across different political groups 


\title{
Acknowledgements
}

Not applicable.

\section{Funding}

This study was supported in part by the Qatar Computing Research Institute. M. Alizadeh was partially and C. Cioffi-Revilla is funded by ONR-Minerva Grant No. N00014130054.

\author{
Abbreviations \\ LIWC, Linguistic Inquiry and Word Count; LW, Left-Wingers (Liberals); LWE, Left-Wing Extremists; MFD, Moral Foundations \\ Dictionary; MFT, Moral Foundations Theory; RW, Right-Wingers (Conservatives); RWE, Right-Wing Extremists,
}

\section{Availability of data and materials}

The datasets generated and analyzed during the current study are not publicly available due to the Twitter's Developer Agreement. However, the user IDs and tweet IDs are available from the corresponding author on request.

\section{Competing interests}

The authors declare no competing interests.

\section{Authors' contributions}

All authors contributed to the design of the study. MA and IW collected the data. MA analyzed the data. All authors contributed to the manuscript. All authors read and approved the final manuscript.

\section{Author details}

'Empirical Studies of Conflict Project, Woodrow Wilson School of Public and International Affairs, Princeton University, Princeton, USA. ${ }^{2}$ Qatar Computing Research Institute, Doha, Qatar. ${ }^{3}$ Computational Social Science Program, Department of Computational and Data Sciences, George Mason University, Fairfax, USA. ${ }^{4}$ Center for Complex Networks and Systems Research, School of Informatics, Computing, and Engineering, Indiana University, Bloomington, USA. ${ }^{5}$ Social Dynamics Laboratory, Department of Sociology, Cornell University, Ithaca, USA.

\section{Publisher's Note}

Springer Nature remains neutral with regard to jurisdictional claims in published maps and institutional affiliations.

\section{Received: 25 December 2017 Accepted: 25 April 2019 Published online: 14 May 2019}

\section{References}

1. Adorno TW, Frenkel-Brunswik E, Levinson DJ, Sanford RN (1950) The authoritarian personality. Harper, New York

2. Alizadeh M, Cioffi-Revilla C, (2014) Distributions of opinion and extremist radicalization: Insights from agent-based modeling. In: The 6th International Conference on Social Informatics, pp 348-358

3. Alizadeh M, Cioffi-Revilla C (2015) Activation regimes in opinion dynamics: comparing asynchronous updating schemes. J Artif Soc Soc Simul 18(3):8

4. Alizadeh M, Cioffi-Revilla C, Crooks AT (2015) The effect of in-group favoritism on the collective behavior of individuals' opinions. Adv Complex Syst 18(01n02):1550002

5. Alizadeh M, Cioffi-Revilla C, Crooks AT (2017) Generating and analyzing spatial social networks. Comput Math Organ Theory 23(3):362-390

6. Alizadeh M, Coman A, Lewis M, Cioffi-Revilla C (2014) Intergroup conflict escalation leads to more extremism. J Artif Soc Soc Simul 17(4):4

7. Alquist JL, Ainsworth SE, Baumeister RF (2013) Determined to conform: disbelief in free will increases conformity. J Exp Soc Psychol 49:80-86. https://doi.org/10.1016/j.jesp.2012.08.015

8. Altemeyer B (1996) The authoritarian specter. Harvard University Press, Cambridge

9. Altemeyer B (1998) The other "authoritarian personality". In: Zanna MP (ed) Advances in experimental social psychology, vol 30. Academic Press, San Diego, pp 47-92

10. Arlow J (2019) Antifa without fascism: the reasons behind the anti-fascist movement in Ireland. Ir Polit Stud 1-23

11. Atran S, Ginges J (2012) Religious and sacred imperatives in human conflict. Science 336(6083):855-857

12. Barberá $P$ (2015) Birds of the same feather tweet together: Bayesian ideal point estimation using Twitter data. Polit Anal 23(1):76-91

13. Beinart P (2017) The rise of the violent left: Antifa's activists say they're battling burgeoning authoritarianism on the American right. Are they fueling it instead? The Atlantic's Politics and Policy. September. https://www.theatlantic.com/magazine/archive/2017/09/the-rise-of-the-violent-left/534192/

14. Bobbio N (1996) Left and right: the significance of a political distinction. University of Chicago Press, Chicago

15. Bonikowski B (2016) Nationalism in settled times. Annu Rev Sociol 42:427-449

16. Butler JC (2000) Personality and emotional correlates of right-wing authoritarianism. Soc Behav Pers Int J 28(1):1-14

17. Canetti-Nisim D, Halperin E, Sharvit K, Hobfoll SE (2009) A new stress-based model of political extremism personal exposure to terrorism, psychological distress, and exclusionist political attitudes. J Confl Resolut 53(3):363-389

18. Castelli Gattinara P, O'Connor F, Lindekilde L (2018) No country for acting alone? The neo-fascist movement and lone-actor terrorist attacks in Italy. Perspect Terror 12(6):136-148

19. Chung C, Pennebaker JW (2007) The psychological functions of function words. Soc Commun 1:343-359

20. Clifford S, Jerit J (2013) How words do the work of politics: Moral foundations theory and the debate over stem cell research. J Polit 75(3):659-671

21. Conover MD, Gonçalves B, Flammini A, Menczer F (2012) Partisan asymmetries in online political activity EPJ Data Sci 1(1):6 
22. Coppersmith G, Harman C, Dredze M (2014) Measuring post traumatic stress disorder in Twitter. In: Eighth international AAAI conference on weblogs and social media

23. Crowson HM, Thoma SJ, Hestevold N (2005) Is political conservatism synonymous with authoritarianism?. J Soc Psychol 145(5):571-592

24. Davidson T, Warmsley D, Macy MW, Weber I (2017) Automated hate speech detection and the problem of offensive language. arXiv preprint. arXiv:1703.04009

25. Davies CL, Sibley CG, Liu JH (2014) Confirmatory factor analysis of the moral foundations questionnaire. Soc Psychol 45:431-436

26. Davis CA, Varol O, Ferrara E, Flammini A, Menczer F (2016) Botornot: a system to evaluate social bots. In: Proceedings of the 25th international conference companion on World Wide Web. International World Wide Web Conferences Steering Committee, pp 273-274

27. Day MV, Fiske ST, Downing EL, Trail TE (2014) Shifting liberal and conservative attitudes using moral foundations theory. Pers Soc Psychol Bull 40(12):1559-1573

28. De Choudhury M, Gamon M, Counts S, Horvitz E (2013) Predicting depression via social media. In: Seventh international AAAl conference on weblogs and social media

29. Dollard J, Doob LW, Miller NE, Mowrer OH, Sears RR (1939) Frustration and aggression. Yale University Press, New Haven

30. Duckitt J (2001) A dual-process cognitive-motivational theory of ideology and prejudice. In: Zanna MP (ed) Advances in experimental social psychology, vol 33. Academic Press, San Diego, pp 41-113

31. Duriez B, Klimstra TA, Luyckx K, Beyers W, Soenens B (2012) Right-wing authoritarianism: protective factor against or risk factor for depression? Eur J Pers 26(5):536-549

32. Enstad JD (2018) Right-wing terrorism and violence in Putin's Russia. Perspect Terror 12(6):89-103

33. Ferrara E (2017) Computational social science to gauge online extremism. arXiv preprint. arXiv:1701.08170

34. Fibert Z, Ressler WH (1998) Intolerance of ambiguity and political orientation among Israeli university students. J Soc Psychol 138(1):33-40

35. Flache A, Macy MW (2011) Small worlds and cultural polarization. J Math Sociol 35(1-3):146-176

36. Frenkel-Brunswik E (1949) Intolerance of ambiguity as an emotional and perceptual personality variable. J Pers 18(1):108-143

37. Graham J, Haidt J (2012) Sacred values and evil adversaries: a moral foundations approach. In: The social psychology of morality: exploring the causes of good and evil, pp 11-31

38. Graham J, Haidt J, Nosek BA (2009) Liberals and conservatives rely on different sets of moral foundations. J Pers Soc Psychol 96:1029

39. Greenberg J, Jonas E (2003) Psychological motives and political orientation-the left, the right, and the rigid: comment on Jost et al. (2003)

40. Greenberg J, Jonas E (2003) Psychological and political orientation—-the left, the right, and the rigid: comment on Jost et al. (2003). Psychol Bull 129:376-382.

41. Greenberg J, Pyszczynski T, Solomon S, Rosenblatt A, Veeder M, Kirkland S, Lyon D (1990) Evidence for terror management theory II: the effects of mortality salience on reactions to those who threaten or bolster the cultural worldview. J Pers Soc Psychol 58(2):308

42. Greenberg J, Solomon S, Pyszczynski T (1997) Terror management theory of self-esteem and cultural worldviews: empirical assessments and conceptual refinements. Adv Exp Soc Psychol 29:61-139

43. Haidt J (2012) The righteous mind: why good people are divided by politics and religion. Vintage

44. Haidt J, Graham J (2007) When morality opposes justice: conservatives have moral intuitions that liberals may not recognize. Soc Justice Res 20(1):98-116

45. Haidt J, Joseph C (2004) Intuitive ethics: how innately prepared intuitions generate culturally variable virtues. Daedalus 133(4):55-66

46. Imai K, Ratkovic M (2014) Covariate balancing propensity score. J R Stat Soc, Ser B, Stat Methodol 76(1):243-263

47. Imbens GW (2004) Nonparametric estimation of average treatment effects under exogeneity: a review. Rev Econ Stat 86(1):4-29

48. Jasko K, LaFree G, Kruglanski AW (2016) Quest for significance and violent extremism: the case of domestic radicalization. Polit Psychol 38(5):815-831

49. Jost JT (2017) Ideological asymmetries and the essence of political psychology. Polit Psychol 38(2):167-208

50. Jost JT, Banaji MR (1994) The role of stereotyping in system-justification and the production of false consciousness. Br J Soc Psychol 33(1):1-27

51. Jost JT, Glaser J, Kruglanski AW, Sulloway FJ (2003) Political conservatism as motivated social cognition. Psychol Bull 129:339-375

52. Jost JT, Hunyady O (2002) The psychology of system justification and the palliative function of ideology. Eur Rev Soc Psychol 13:111-153

53. Jost JT, Napier JL, Thorisdottir H, Gosling SD, Palfai TP, Ostafin B (2007) Are needs to manage uncertainty and threat associated with political conservatism or ideological extremity? Pers Soc Psychol Bull 33(7):989-1007

54. Kang JD, Schafer JL (2007) Demystifying double robustness: a comparison of alternative strategies for estimating a population mean from incomplete data. Stat Sci 22(4):523-539

55. Kitsak M, Gallos LK, Havlin S, Chen X, Liljeros F, Muchnik L, Stanley HE Makse HA (2010) Identification of influential spreaders in complex networks. Nat Phys 6(11):888-893. https://doi.org/10.1038/nphys1746

56. Koehler D (2018) Recent trends in German right-wing violence and terrorism: what are the contextual factors behind 'hive terrorism'? Perspect Terror 12(6):72-88

57. Kruglanski AW (2013) The psychology of closed mindedness. Psychology Press

58. Kruglanski AW, Gelfand M, Gunaratna R (2012) Terrorism as means to an end: how political violence bestows significance. In: Shaver PR, Mikulincer M (eds) Meaning, mortality, and choice: the social psychology of existential concerns. American Psychological Association, Washington, pp 203-212

59. Kruglanski AW, Jasko K, Chernikova M, Dugas M, Webber D (2017) To the fringe and back: violent extremism and the psychology of deviance. Am Psychol 72:217-230 
60. Kruglanski AW, Webster DM (1996) Motivated closing of the mind: "seizing" and "freezing". In: The motivated mind. Routledge, London, pp 68-111

61. Kurzman C, Kamal A, Yazdiha H (2017) Ideology and threat assessment: law enforcement evaluation of muslim and right-wing extremism. Socius 3:2378023117704771

62. LaFree $\mathrm{G}(2018)$ Is Antifa a terrorist group? Society 55(3):248-252

63. Macklin G (2018) 'Only bullets will stop us!'- - the banning of national action in Britain. Perspect Terror 12(6):104-122

64. Magdy W, Darwish K, Weber I (2016) \#FailedRevolutions: using Twitter to study the antecedents of ISIS support. First Monday 21:2

65. Mareš M (2018) Right-wing terrorism and violence in Hungary at the beginning of the 21st century. Perspect Terror 12(6):123-135

66. Napier JL, Jost JT (2008) Why are conservatives happier than liberals? Psychol Sci 19(6):565-572

67. Nilsson A, Erlandsson A (2015) The moral foundations taxonomy: structural validity and relation to political ideology in Sweden. Pers Individ Differ 76:28-32

68. Onraet E, Van Hiel A, Dhont K (2013) The relationship between right-wing ideological attitudes and psychological well-being. Pers Soc Psychol Bull 39(4):509-522

69. Pennebaker JW, Boyd RL, Jordan K, Blackburn K (2015) The development and psychometric properties of LIWC2015

70. Pennebaker JW, Francis ME, Booth RJ (2001) Linguistic inquiry and word count: LIWC 2001. Lawrence Erlbaum Associates 71 , Mahway.

71. Pennebaker JW, Mehl MR, Niederhoffer KG (2003) Psychological aspects of natural language use: Our words, our selves. Annu Rev Psychol 54(1):547-577

72. Peterson BE, Duncan LE (2007) Midlife women's generativity and authoritarianism: marriage, motherhood, and 10 years of aging. Psychol Aging 22(3):411

73. Pierce WL (1978) The Turner diaries. National Vanguard Books, Hillsboro

74. Poole KT, Rosenthal H (1985) A spatial model for legislative roll call analysis. Am J Polit Sci 29:357-384

75. Pratto F, Sidanius J, Stallworth LM, Malle BF (1994) Social dominance orientation: a personality variable predicting social and political attitudes. J Pers Soc Psychol 67(4):741

76. Prince J (2016) Psychology of extremism. Extremism, counter-terrorism and policing, 51

77. Ravandi B, Mili F (2019) Coherence and polarization in complex networks. J Comput Soc Sci, 1-18

78. Roccato M, Russo S (2017) Right-wing authoritarianism, societal threat to safety, and psychological distress. Eur J Soc Psychol 47:600-610

79. Rokeach M (1960) The open and closed mind. Basic Books, New York

80. Rosenbaum PR, Rubin DB (1983) The central role of the propensity score in observational studies for causal effects. Biometrika 70(1):41-55

81. Rowe M, Saif H (2016) Mining pro-ISIS radicalisation signals from social media users. In: Proceedings of the tenth international AAAI conference on web and social media (ICWSM 2016), pp 329-338

82. Shao C, Hui PM, Wang L, Jiang X, Flammini A, Menczer F, Ciampaglia GL (2018) Anatomy of an online misinformation network. arXiv preprint. arXiv:1801.06122

83. Sidanius J (1985) Cognitive functioning and sociopolitical ideology revisited. Polit Psychol 6:637-661

84. Sidanius J (1988) Political sophistication and political deviance: a structural equation examination of context theory. J Pers Soc Psychol 55(1):37

85. Sinnenberg L, Buttenheim AM, Padrez K, Mancheno C, Ungar L, Merchant RM (2017) Twitter as a tool for health research: a systematic review. Am J Publ Health 107(1):e1-e8

86. Smith JA, Todd PE (2005) Does matching overcome LaLonde's critique of nonexperimental estimators? J Econom 125(1-2):305-353

87. Smith MR, Gordon RA (1998) Personal need for structure and attitudes toward homosexuality. J Soc Psychol 138(1):83-87

88. Sorrentino RM, Roney CJ (1986) Uncertainty orientation, achievement-related motivation, and task diagnosticity as determinants of task performance. Social Cogn 4(4):420-436

89. Stuart EA (2010) Matching methods for causal inference: a review and a look forward. Stat Sci 25(1):1

90. Sweeney MM, Perliger A (2018) Explaining the spontaneous nature of far-right violence in the United States. Perspect Terror 12(6):52-71

91. Tajfel H (1982) Social identity and intergroup relations. Cambridge University Press, Cambridge

92. Taylor P, Funk C, Craighill P (2006) Are we happy yet? Retrieved April 3, 2018, from the Pew Research Center website: http://www.pewsocialtrends.org/2006/02/13/are-we-happy-yet/

93. Tetlock PE (1984) Cognitive style and political belief systems in the British House of Commons. J Pers Soc Psychol 46:365-375

94. Tomkins SS (1963) Left and right: a basic dimension of ideology and personality. In: White RW (ed) The study of lives. Atherton, Chicago, pp 388-411

95. Van Hiel A, De Clercq B (2009) Authoritarianism is good for you: right-wing authoritarianism as a buffering factor for mental distress. Eur J Pers 23(1):33-50

96. van Prooijen JW, Krouwel AP, Boiten M, Eendebak L (2015) Fear among the extremes how political ideology predicts negative emotions and outgroup derogation. Pers Soc Psychol Bull 4:0146167215569706

97. Vargas-Salfate S, Paez D, Khan SS, Liu JH, de Zúñiga HG (2018) System justification enhances well-being: a longitudinal analysis of the palliative function of system justification in 18 countries. Br J Soc Psychol 57:567-590

98. Varol O, Ferrara E, Davis CA, Menczer F, Flammini A (2017) Online human-bot interactions: detection, estimation, and characterization. arXiv preprint. arXiv:1703.03107

99. Webber D, Babush M, Schori-Eyal N, Vazeou-Nieuwenhuis A, Hettiarachchi M, Bélanger JJ, Moyano M, Trujillo HM, Gunaratna R, Kruglanski AW, Gelfand MJ (2018) The road to extremism: field and experimental evidence that significance loss-induced need for closure fosters radicalization. J Pers Soc Psychol 114:270-285

100. Westen D (2008) The political brain: the role of emotion in deciding the fate of the nation. Public Affairs

101. Windisch S, Simi P, Blee K, DeMichele M (2018) Understanding the micro-situational dynamics of white supremacist violence in the United States. Perspect Terror 12(6):23-37 
102. Yilmaz O, Harma M, Bahçekapili HG, Cesur S (2016) Validation of the moral foundations questionnaire in Turkey and its relation to cultural schemas of individualism and collectivism. Pers Individ Differ 99:149-154

103. Zhao WX, Jiang J, Weng J, He J, Lim EP, Yan H, Li X (2011) Comparing Twitter and traditional media using topic models. In: European conference on information retrieval. Springer, Berlin, pp 338-349

Submit your manuscript to a SpringerOpen ${ }^{\circ}$ journal and benefit from:

- Convenient online submission

- Rigorous peer review

- Open access: articles freely available online

- High visibility within the field

- Retaining the copyright to your article

Submit your next manuscript at $\gg$ springeropen.com 